\title{
Puget Sound Area Electric Reliability Plan
}

Scoping Summary Report - Part B Preliminary Technical Analysis Appendix A

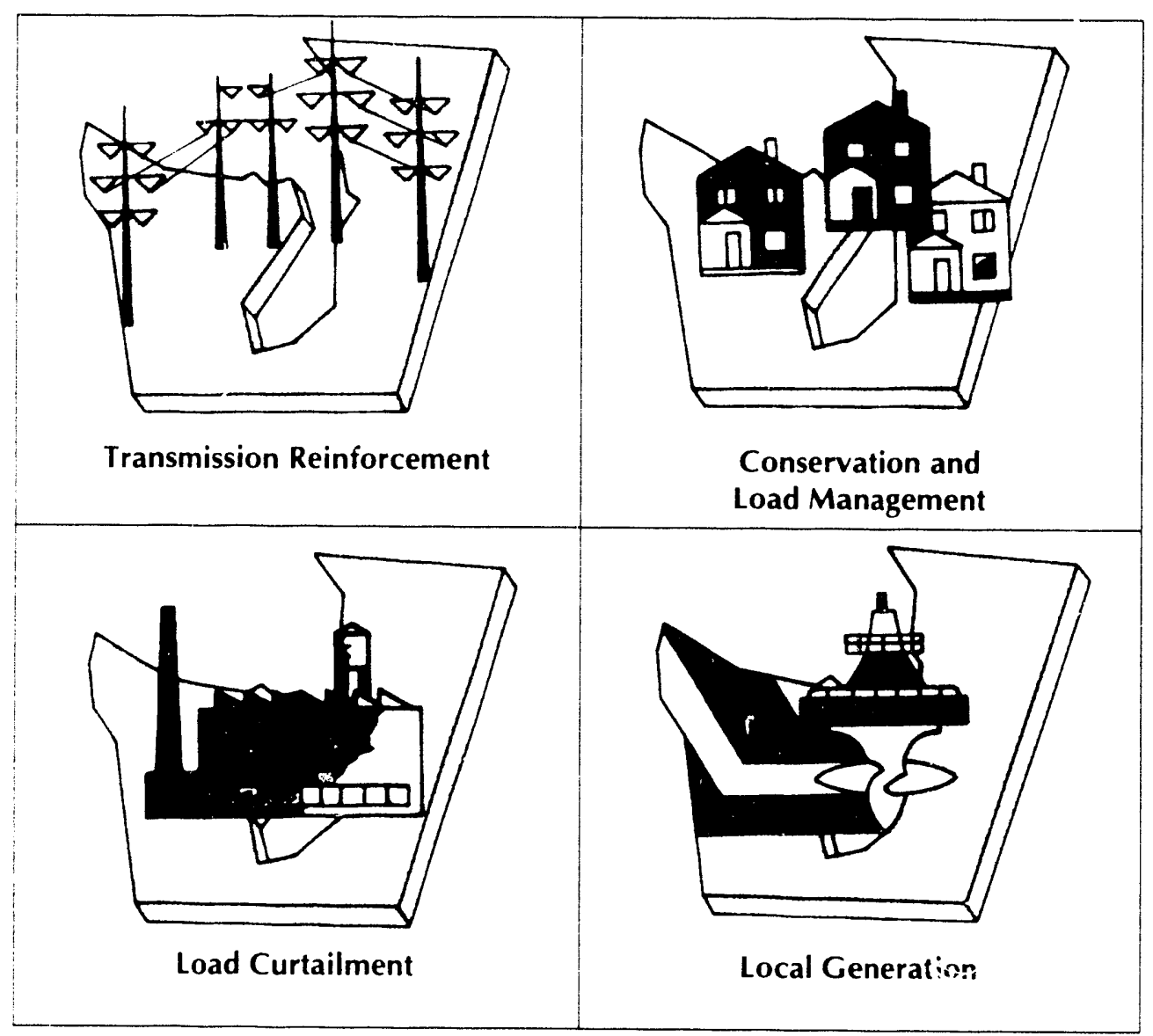


DOE/BP--1703

DE92 003501

\title{
DRAFT ENVIRONMENTAL IMPACT STATEMENT
}

\section{PUGET SOUND AREA ELECTRIC RELIABILITY PLAN}

\author{
Appendix A \\ Preliminary Technical Analysis
}

\section{Bonneville Power Administration \\ U.S. Department of Energy}

Prepared as part of a coordinated plan to address a power system problem in the Puget Sound Area. Utilities participating in planning include: Bonneville Power Administration, Puget Sound Power and Light, Seattle City Light, Snohomish County Public Utility District No. 1, and Tacoma City Light. 
PUGET SOUND AREA ELECTRIC RELIABILITY PLAN SCOPING REPORT PART B: PRELIMINARY TECHNICAL ANALYSES

T A B L E O F C O N T E N T S

Introduction

1

I. Problem Statement 4

II. Puget Sound Area Load Forecast 6

III. Puget Sound Area Power System Capacity 21

IV. Measure Categories 32

A. Conservation \& Load Management 34

B. Local Generation 44

C. Transmission 51

D. Load Curtailment $\quad 57$

V. Evaluation Methodology 65

VI. Next Steps - Phase II 71 


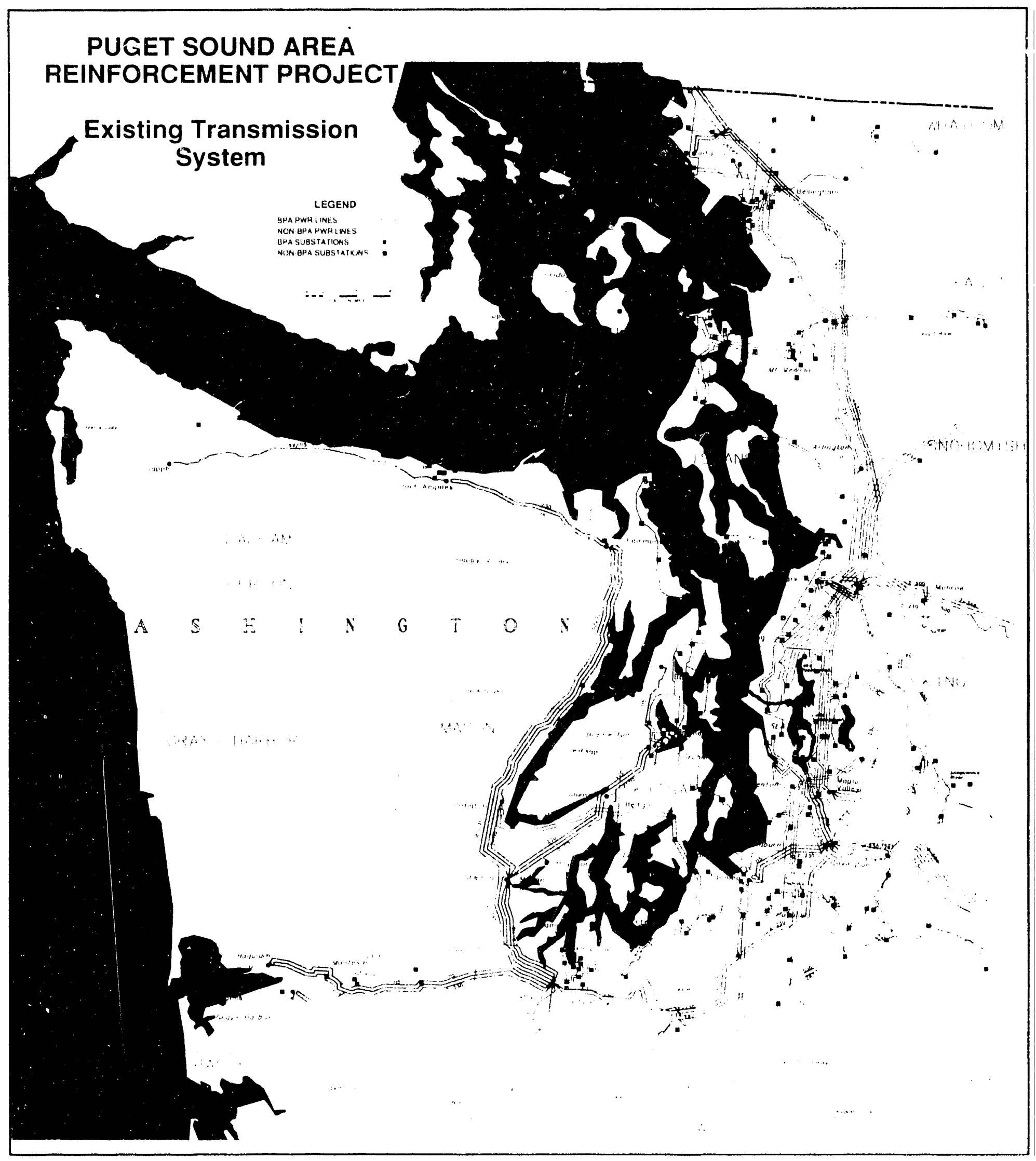




\author{
INTRODUCTION
}

Background. In December 1989 Bonneville Power Administration (BPA) published an Issue Alert entitled "The Search for a Sound Solution (to Potential Voltage Collapse in the Puget Sound Area)." The publication described a voltage instability problem in the Puget Sound area (*). It also announced the initiation of a study and two-phase planning process which will lead to a proposal for actions, if any, that need to be taken to address the problem. This preliminary technical analysis, along with a companion public comment summary, documents the first phase of the process, "scoping."

Phase I: Scoping. Phase I was designed to serve several purposes: 1) to confirm the existence of a voltage instability problem in the Puget Sound area; 2) to notify the public of the existence of the problem and to begin to involve interested members of the public in the study; 3 ) to define the problem in terms that would allow analysis of alternative solutions; 4) to identify measures that could compose alternative solutions; and 5) to perform preliminary feasibility studies on the measures identified.

Phase I began with a series of public scoping meetings designed to inform interested i.sdividuals and organizations of the upcoming planning process, to obtain comments on the proposed study, and to solicit involvement in the review of study results.

In order to identify and analyze potential measures BPA sought the participation of the four largest retail utilities in the area, Puget Sound Power and Light Company, Seattle City Light, Tacoma City Light, and Snohomish Public Utility District (PUD). BPA and each of the four utilities entered into an agreement to conduct the study as a joint project. A copy of the agreement is included as an appendix to this report. The active participation of these utilities has been vital to the completion of the preliminary analyses and will continue to be essential during the evaluation, decision, and implementation processes. It should be noted, however, that this study does not replace individual utility planning, nor should it be confused with BPA's Resource Program or the Northwest Power Planning Council's plan.

Numerous other individuals and organizations have been involved in shaping the study plan and reviewing interim results through periodic technical review group meetings. In addition, over fifty individuals have submitted written comments. A detailed description of Phase I, including a discussion of the technical review group, is provided in the Scoping Report, Part A: Public Comment Summary.

(*) For the purpose of this study, the puget Sound area is defined as the electrical service area extending north to the Canadian border, east to the Cascade Mountains, south to Chehalis, and west to the Pacific Ocean. 
Phase I will conclude in August 1990 with the adoption of this report, incorporating any revisions resulting from public review. During Phase II the most promising alternatives will be evaluated in detail. Phase II is described in Chapter VI, "Next Steps."

National Environmental Pulicy Act (NEPA) Process. The results of the entire evaluation process will be documented in a BPA Environmental Impact Statement (EIS) to be circulated in draft in March 1991. A final planning EIS will be published by BPA in the fall of 1991, followed by a Record of Decision. As specific actions are proposed, additional project and site-specific environmental analyses may be required. For a detailed description and schedule of the NEPA process, see Part A of this Scoping Report. Part A also discusses EIS scoping and public involvement activities to date.

Study Organization. Because this problem affects the entire electric power delivery system in the Puget Sound area, not just BPA's transmission grid, wide participation within the area is crucial. Early in the process, study teams were formed to address all aspects of the problem as well as the potential solutions. Each study team is made up of representatives from BPA and each of the four major utilities serving the Puget Sound area. (Puget Sound Power and Light Company, Seattle City Light, Tacoma City Light, and Snohomish PUD) These utilities represent about 80 percent of the area's electricity sales.

A steering committee composed of BPA and utility members provides policy guidance. A project management team directs the efforts of eight study teams. The load forecast team prepared the Puget Sound area load forecasts required for the analysis. The evaluation team designed screening criteria for the individual measures and an evaluation methodology to be applied to alternative strategies. Four teams were created to identify and screen measures. These include the conservation and load management team, the transmission team, the local generation team, and the load curtailment team. Finally, NEPA and public involvement teams guide aspects of the study process.

In addition, a technical review group, representing state and local government, business and industry, public interest groups, and the general public, was formed to provide input and review study team results. Some members of the technical review group participated direcliy in the analyses. A detailed description of the technical review group is included in Part $A$ of this Scoping Report.

As the study progressed, subgroups of the technical review group reviewed interim products and provided input. Public meetings were held to discuss the voitage instability problem, the load forecast, the evaluation methods, and preliminary results of the measure analysis. A public comment period allcwed the inclusion of written comments. Each of the utilities and aumerous members of the public contributed to this effort. 
Study Method. The study teams began by identifying all available options--measures, technologies, and programs--within each of the four measure categories. They employed various techniques, but most reviewed available sources, including the latest BPA and Northwest Power Planning Council studies, rather than conducting new research. All teams relied heavily on information supplied by the utilities concerning previous experience and future plans. Technical review group input and written comments supplemented the study teams' efforts. Individual study team methodologies are discussed under each section in Chapter IV, "Measure Categories."

Screening criteria were applied to each measure identified, narrowing the lists to the most promising alternatives within each measure categury. These are the measures that the study teams propose for evaluation in Phase II of the study. The measures that survive the initial screening are described in more detail than those in the original list of measures considered. The descriptions inslude estimates of cost, quantity, and availability for each measure. Scrsening criteria are discussed in Chapter IV, "Measure Categories."

An important consequence of the study method is that during Phase I options were screened within each measure category. No comparison across measure categories has yet occurred. Thus, the measures described in Chapter IV represent the study teams' assessment of the strongest proposals within their area of consideration. It has not been established that any one or more of these measures will "solve" the Puget Sound voltage instability problem. During Phase II, alternative strategies, composed of elements from one or more categories, will be developed. At this point a complete evaluation of each strategy and its component measures will be conducted.

Report Organization. Chapter I describes in general terms the nature of the voltage instability problem facing the Puget Sound area. The following two chapters cover the technical aspects of the problem. Chapter II deals with load growth, the root cause of the problem. Chapter III addresses the capacity of the current power system and the criteria for future system planning. It also explains the technical results of transmission system modeling which confirm the system's vulnerability to voltage instability, the principal symptom of the problem.

Chapter IV provides the results of the scoping process in each of the four measure categories. Included are iists of al1 options identified, a discussion of the screening criteria, and descriptions of the measures that survived the screening process and are proposed for further evaluation in Phase II.

Chapter $V$ discusses the evaluation methodology which will be used to refine the analyses. Chapter VI outlines the next steps in the planning process. It also describes the short cerm operational agreements that will assure continued reliable service until a long term solution is in place. 


\section{PROBLEM STATEMENT}

Introduction. During Phase I the utility study team worked to confirm the potential for a voltage instability problem in the Puget Sound area. The first task in Phase II will be to refine understanding of the problem and to define it in terms that will allow analysis of alternative solutions. This section introduces the main components of the problem and describes the current situation in the Puget Sound area that has led to the initiation of this study. Technical discussions of the problem are provided in Chapter II, "Puget Sound Area Load Forecast" and Chapter III, "Puget Sound Area Fower System Capacity." Chapter III also describes the phenomena of voltage instability and voltage collapse in more detail.

Background. In late January and early February 1989 the Puget Sound area experienced extreme cold temperatures and record peak electricity loads. The cold wave lasted for a week and was unusually widespread, making a strong impression on the entire Pacific Northwest. It has come to be known as the "Siberian Express."

The 1989 peak severely tested the power system throughout the region. The transmission grid met the challenge and performed as expected. Although some generation was out of service and minor disturbances occurred, there were no major transmission line losses. The system was able to overcome the problems that did occur. Had there been a major line loss, a very low-probability event, some loads would have had to be cut off to protect the system.

The Risk of Voltage Collapse. The arrival of the Siberian Express, though unwelcome at the time, offered a rare opportunity for Northwest utilities to study the performance of their systems under stress. The record peak loads provided actual data to substantiate or revise projections of system performance.

Preliminary analysis of these data suggested that under peak loading conditions, the main grid transmission system that brings power from east of the Cascades into the Puget Sound area will no longer be able to support the area's rapidly growing electrical loads. For example, during conditions of peak winter demand, the system may not adequately withstand failure of a major transmission line or a major local generating resource.

Three principal elements have contributed to this situation.

1) Rapid Load Growth, Unprecedented Peak Demand. Strong, sustained economic growth has led to rapidly increasing electricity loads in the Puget Sound area. In 1985, loads were growing at 2 percent per year; by 1989 the growth rate had increased to nearly 4 percent. As energy use increases, peak demand on the power system grows also. During unusually cold weather in February 1989, loads peaked at almost 11,000 megawatts (MW). In 1990, a mild winter, peak loads reached 10,380 MW. Peak loads are projected to grow between 200 and 400 MW a year. Although the growth rate is expected to slow somewhat, even current peak loads can strain the transmission system to its 1 imits. 
2) Heavy Reliance on Transmission. Puget Sound is heavily dependent on long distance transmission from east of the Cascades. High voltage lines transmit about $3 / 4$ of the power used to serve Puget Sound area peak demand for electricity. Five BPA $500 \mathrm{kV}$ lines running through two corridors in the Cascades carry the bulk of this power. There have been no major $500 \mathrm{kV}$ transmission additions to the Puget Sound area since 1977. The existing transmission network was designed assuming that additional generation would be built locally. As described below, this has not happened.

3) Scant Local Generation. Only 3,500 MW of generating capacity is located within the Puget Sound area, compared to the 1989 winter peak load of $11,000 \mathrm{MW}$. Generating projects that were planned in the 1960's \& $70^{\prime} \mathrm{s}$ were not completed when surplus capacity in the $1980^{\prime} \mathrm{s}$ made additional construction unnecessary. Although Northwest regional generating capacity is still adequate, the lack of local generation has led to the current dependence on transmission from dams and thermal projects east of the Cascades.

The combination of heavy demand for electricity, little local generation, and long, heavily loaded transmission lines may lead to voltage instability. Voltage support that would normally be provided by generation must be provided through auxiliary equipment, such as capacitor banks. When loads are very heavy and voltage drops, capacitor banks become less effective. If a major system component fails during peak demand, voltage can drop below acceptable levels, causing a brownout. In extreme cases, automatic devices will protect the system by disconnecting lines, leading to lower and lower voltages. This phenomenon, which will black out consumers, is known as voltage collapse. If not arrested, the effects could extend throughout the Puget Sound area and beyond to the Portland, Oregon and Vancouver, British Columbia load areas. In the future, as peak loads grow and the transmission system is strained further, smaller, more common and frequent disturbances will pose the threat of voltage collapse.

Reliability Criteria. BPA and other utilities design their transmission systems to meet high standards of performance under a variety of contingencies. Contingencies include loss of generation, transmission line outages, and other major equipment failure. Required performance levels vary according to weather conditions and equipment constraints, but in general, load loss is allowed only in case of very unusual events.

An underlying planning principle is that load loss should be avoided unless the cost to maintain acceptable performance exceeds the expected cost of outages to the consumer. While it is impossible to know exactly when this balance is met, planners use rules based on their experience, tabulated in the reliability criteria. This practice has resulted in an extremely reliable system. Because of carefully planning, consumers rarely feel the effects of transmission system disturbances.

In the Puget Sound area, however, the transmission system fails some reliability tests. While this does not mean that system failure is imminent, there is currently an unacceptable risk of voltage collapse. 


\section{I. PUGET SOUND AREA LOAD FORECAST}

Introduction. This chapter discusses the peak load forecasts prepared by the load forecast team composed of forecasters from the major Puget Sound area utilities and BPA. Forecasts were prepared at both the aggregate system level and the consuming sector/end-use level. The chapter describes recent Puget Sound area peak loads and presents the system and sector forecasts.

These forecasts will be used in a variety of ways. The transmission study team will use the system forecasts to perform power flow studies to determine whether reliability criteria are met. They will also use the sector and end-use forecasts to do more detailed modeling of transmission system performance under varying load conditions.

The conservation and load management study team will use the sactor and end-use forecasts to assess various load management and conservation program proposals. The curtailment team will use the end-use forecasts to gauge the net impact of plant or building closures. The evaluation team will use the forecasts to analyze alternative strategies (combinations of measures) and assess how load forecast uncertainties affect evaluation results.

Recent Experience. In late January 1989 an arctic air mass moved into the Pacific Northwest. Tomperatures plummeted, sending electricity demand soaring to record levels. In the Puget Sound area electricity demand peaked at 9:00 a.m. on February 3rd at almost 11,000 MW. The minimum temperature on this day was $10^{\circ} \mathrm{F}$ with an average temperature of $14^{\circ} \mathrm{F}$. The peak electricity demand for the winter of 1990 occurred on February 14th, a day of relatively normal temperatures (a minimum temperature of $22^{\circ} \mathrm{F}$, daily average of $27^{\circ} \mathrm{F}$ ) in the Puget Sound area, at 8:00 a.m. at about 10,400 MW.

The hourly loads recorded on these two days are depicted graphically in Figure II-1 and presented numerically in Table II-1. While the daily load shapes are similar for the two days, there are some differences. For both days the shape is bimodal with morning and evening peaks. However the peak occurs one hour later under extreme conditions. Also in the extreme case the level of the evening peak is much closer to the daily peak than in the normal case. The shape is also flatter in the extreme case, resulting in a daily load factor (daily energy/daily peak) of 0.877 compared to 0.813 for the normal peak day. Another difference is the length of the peak period. Under normal conditions the loads rise sharply from 7:00 a.m. to 8:00 a.m. then drop again at 9:00 a.m. Under extreme conditions however the loads rise sharply from 7:00 a.m. to $8: 00 \mathrm{a} . \mathrm{m}$. and rise slightly from 8:00 a.m. to 9:00 a.m. Loads then decline slightly from 9:00 a.m. to 10:00 a.m. before falling sharply. So rather than a one-hour event as is the case under normal conditions, the extreme case is a three-hour event. The patterns of hourly loads shown in Figure II-1 (February 3, 1989 and February 14, 1990) are characteristic of weekday system loads at extreme and normal temperatures. 


\section{Peak Forecasts}

Normal and Extreme Weather. Puget Sound area electricity loads peak during the winter, so the degree of cold contributes to peak demand. Peak forecasts were developed for normal and extreme winter weather conditions. Normal weather is defined as the lowest daily average temperature which would have a 50 percent chance of being surpassed, that is, one would expect the actual average temperature to be colder once every two years. Extreme is defined as the lowest daily average temperature that has a 5 percent chance of being surpassed; one would expect the actual temperature to be colder once every 20 yars. Average daily temperatures at Sea-Tac for the coldest winter day are $22^{\circ} \mathrm{F}$ under normal conditions and $15^{\circ} \mathrm{F}$ under extreme conditions. Puget Sound area peak electricity loads increase by about 150 MW for each degree Fahrenheit that the average daily temperature drops below normal.

System Results. Over the next 20 years, Puget Sound area peak loads are expected to grow by 3400 MW under normal weather conditions, resulting in a peak of over 13600 MW by the year 2010. Under extreme conditions the peak in the year 2010 would reach 15200 MW. Loads are expected to grow faster during the mid-1990's with extreme peak growth in the 200-400 MW range each year through 1995. Load growth slows after 1995 due to slower economic growth, continuing improvements in energy efficiency, and competition for space and water heating loads from natural gas. The medium case annual peak forecasts are shown in Figure II-2 and Table II-2.

The horizontal stair-step lines indicate the approximate capacity of the Puget Sound area power system given the transmission reliability criteria described in Chapter III. The capacity increases between 1990 and 1993 reflect voltage support additions planned by BPA. With no cross-Cascade transmission 1 ine outage, extreme peak loads are expected to exceed transmission capacity by roughly 1996 under medium load growth. With the voltage support additions in 1993, system capacity with one line out will just meet extreme peak load. System capacity with two lines out is not sufficient to serve normal peak load even after the voltage support additions.

System Methodology. Annual system peaks were forecast by applying load factors to January energy projections by utility for Puget Sound Power and Light, Seattle City Light, Snohomish County Public Utility District, and Tacoma City Light. These utilities provided forecasts of customer growth, market share, and energy use per customer. Separate load factors were derived for each utility for normal and extreme weather conditions. For the nongenerating public utilities and the direct service industries (DSIs), sum-of-utility (SOU) forecasts were used for normal peaks. For extreme peaks a peak adjustment factor was applied to the normal sou peak forecasts. The normal and extreme load factors are based on analysis of utility hourly load data and Sea-Tac temperature data for the 1989 and 1990 winters. The utility energy forecasts (and resulting peak forecasts) reflect the most recent available information on loads and load growth and have been reviewed extensively by utility and BPA forecasters. 
The forecasts described here include the savings associated with current and expected future utility energy conservation programs, including the recently adopted Washington state model conservation standards (MCS), but are not reduced for additional conservation or load management actions that may be part of proposed solutions to the Puget Sound peak load problem.

Sector Results. Sector and end-use detail is presented in Figures II-3 and II-4 and Table II-3. Figure II-3 shows peak growth by end-use for extreme weather conditions. Figure II-4 compares the end-use shares under normal and extreme conditions at the time of system peak for 1990.

Among the sectors, commercial loads are the fastest growing. The average annual growth rate for the commercial sector normal peak from 1990 to 2010 is 3.9 percent. This growth is driven primarily by increases in floor space. Total floor space is forecast to grow by 3.5 percent over the 20 years. The share of office floor space increases from 23 percent in 1990 to 26 percent in 2010. Small increases in saturation of heating, ventilation, and air conditioning systems (HVAC) occur. Modest declines in kilowatthours (kWh) per square foot due to efficiency improvements are forecast for HVAC and 1 ighting end-uses.

Residential normal peak loads grow by only 0.6 percent from 1990 to 2010. This small growth is due to declining electric saturations and increased efficiency in the space and water heat end-uses. Total miscellaneous residential end-uses are forecast to increase slightly. Households are forecast to grow by 2.1 percent with the fastest growth in multi-famiiy buildings. As shown in Figure II-4, residential water heater use declines from the normal to extreme case. This reflects the one-hour shift in the time of the peak as well as behavioral changes between a normal and extremely cold day.

Industrial normal peak is forecast to grow by 2.8 percent. There is no significant growth in the DSI sector.

System load factors for area loads increase from 56 percent in 1990 to 58 percent in 2010 for normal peaks and from 51 percent to 53 percent for extreme peaks. This is a net result of slow growth among end-use loads with low load factors, residential space and water heat, and relatively strong growth in the industrial sector and residential and commercial miscellaneous end-uses which tend to have flatter load shapes. Offsetting the overall trend is strong growth for commercial HVAC, which is weather sensitive but less so than residential space heat.

Sector Methodology. Sector and end-use projections were developed ising housing, commercial floor space, and end-use metered data, much of wh:ch was provided by the Puget Sound area utilities. Sector forecasts were t.nen calibrated to the annual system energy and peak projections descrioed above. The sector forecasts thus represent a disaggregation of the syst:m forecast. 
For the residential and commercial sectors, the end-use energy forecast was determined by multiplying the number of househoids or the commercial square footage by an electric saturation rate. The resulting electric "unit" was multiplied by annual $\mathrm{kWh}$ per electric unit. To derive peaks for these two sectors, annual energy was multiplied by the percentage occurring in January. An average January day was then calculated as January energy divided by

31 days. Normal and extreme peak day energy was determined by multiplying the peak to average January day ratio by the average day. Nornal and extreme peak day hourly shapes were then applied to energy for the relevant day to yield hourly load values for normal and extreme peak days. This methodology was followed for each building type and end-use.

In the utility industrial, DSI, and other sectors, annual energy was divided by a load factor for normal and extreme peak days. A peak day shape was applied to the resulting peaks to yield hourly loads for normal and extreme peak days.

Uncertainty. There are several sources of load uncertainty. These include weather, economic activity, electricity and fossil fuel prices, changes in technology and changing mix of end-uses, among others. The principal sources of uncertainty are weather and overall economic growth. The weather uncertainty was captured by producing peaks under extreme temperature conditions ( 5 percent probability of lower temperatures). The uncertainty associated with economic growth and prices was addressed by providing ranges around the base forecasts. These ranges were derived by applying the percentage deviation from the base case in the 1990 Long-Term Regional Forecast for each scenario to the Puget Sound area base case under normal and extreme conditions.

The ranges under normal conditions are prasented in Table II-4 and Figure II-5. The ranges under extreme conditions are presented in Table II-5 and Figure II- 6 . There is a 5 percent probability of loads exceeding the high forecast or being below the low forecast. There is a 20 percent probability of loads falling between the high and medium-high forecasts or between the medium-10w and low forecasts. There is a 25 percent probability that loads will be between the medium-high and medium forecasts or between the medium and medium-1ow forecasts.

Summary. In general, normal peaks are forecast to grow by about 200 MW per year. Under extreme weatrer conditions, the peaks are projected to be about 1000 MW higher than under normal conditions in the near term, growing to $1300 \mathrm{MW}$ greater by the year 2010. Weather sensitive loads such as residential space heating are projected to grow more slowly than those loads that are not weather sensitive. This results in small declines in weather responsiveness over the forecast horizon. 
Figure II-1

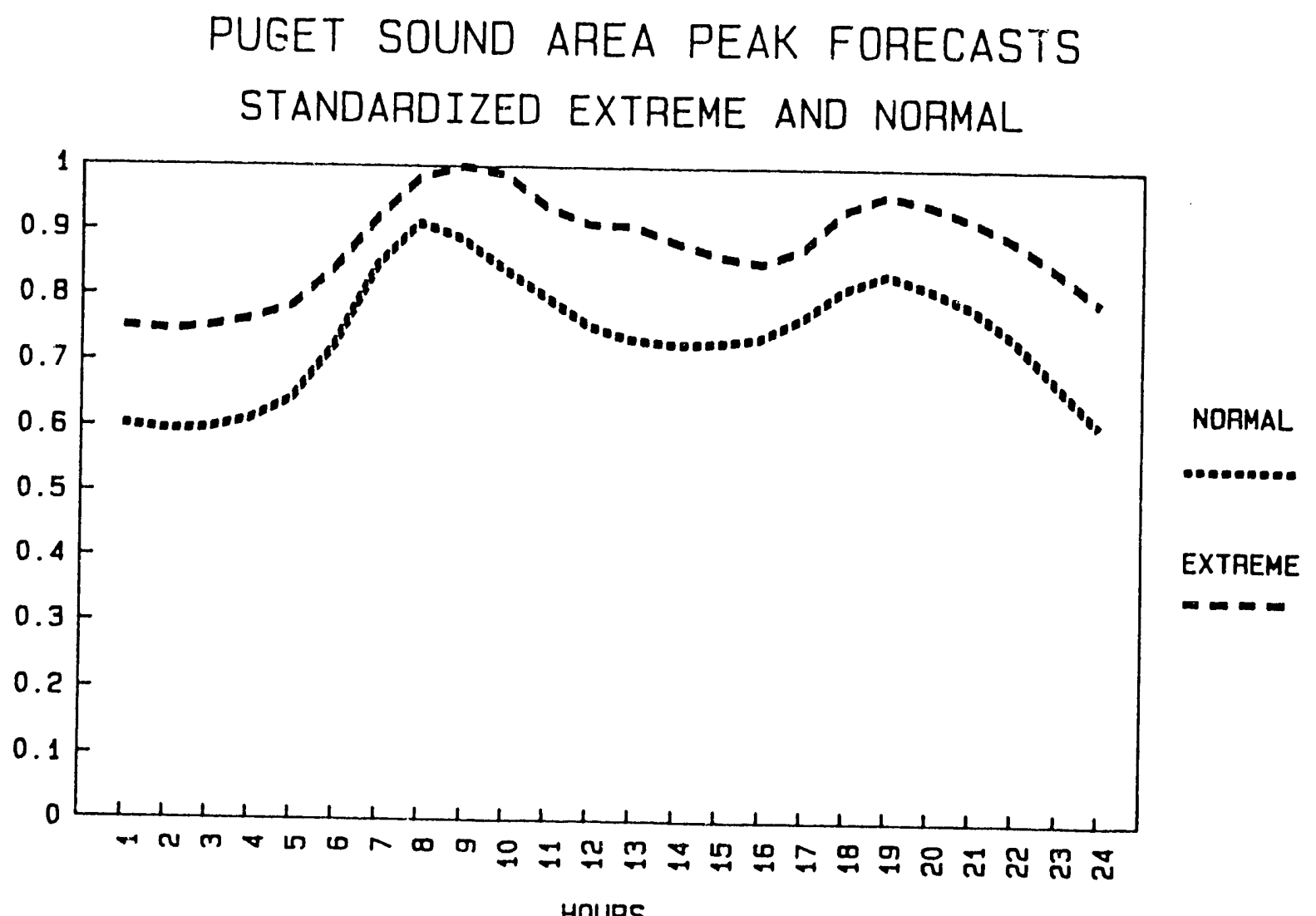
HOURS 


\section{HOURLY LOADS FOR FEBRUARY 3, 1989 AND FEBRUARY 14, 1990}

\begin{tabular}{rrr}
\hline HOUR & $\begin{array}{c}\text { FEBRUARY 3, 1989 } \\
\text { (MEGAWATTS) }\end{array}$ & $\begin{array}{r}\text { FEBRUARY } 14,1990 \\
\text { (MEGAWATTS) }\end{array}$ \\
1 & & \\
2 & 8262 & 6820 \\
3 & 8210 & 6737 \\
4 & 8276 & 6778 \\
5 & 8407 & 6928 \\
6 & 8629 & 7274 \\
7 & 9256 & 8192 \\
8 & 10124 & 9595 \\
9 & 10805 & 10309 \\
10 & 10991 & 10019 \\
11 & 10846 & 9496 \\
12 & 10304 & 9032 \\
13 & 10018 & 8565 \\
14 & 9990 & 8321 \\
15 & 9720 & 8250 \\
16 & 9480 & 8274 \\
17 & 9367 & 8371 \\
18 & 9631 & 8722 \\
19 & 10284 & 9217 \\
20 & 10552 & 9468 \\
21 & 10377 & 9217 \\
22 & 10123 & 8909 \\
23 & 9772 & 8378 \\
24 & 9267 & 7603 \\
& 8741 & 6896 \\
\hline
\end{tabular}


Figure $11-2$

\section{Puget Sound Area Peak Loads}

\section{Historical. Forecast and Transmission Capacity}

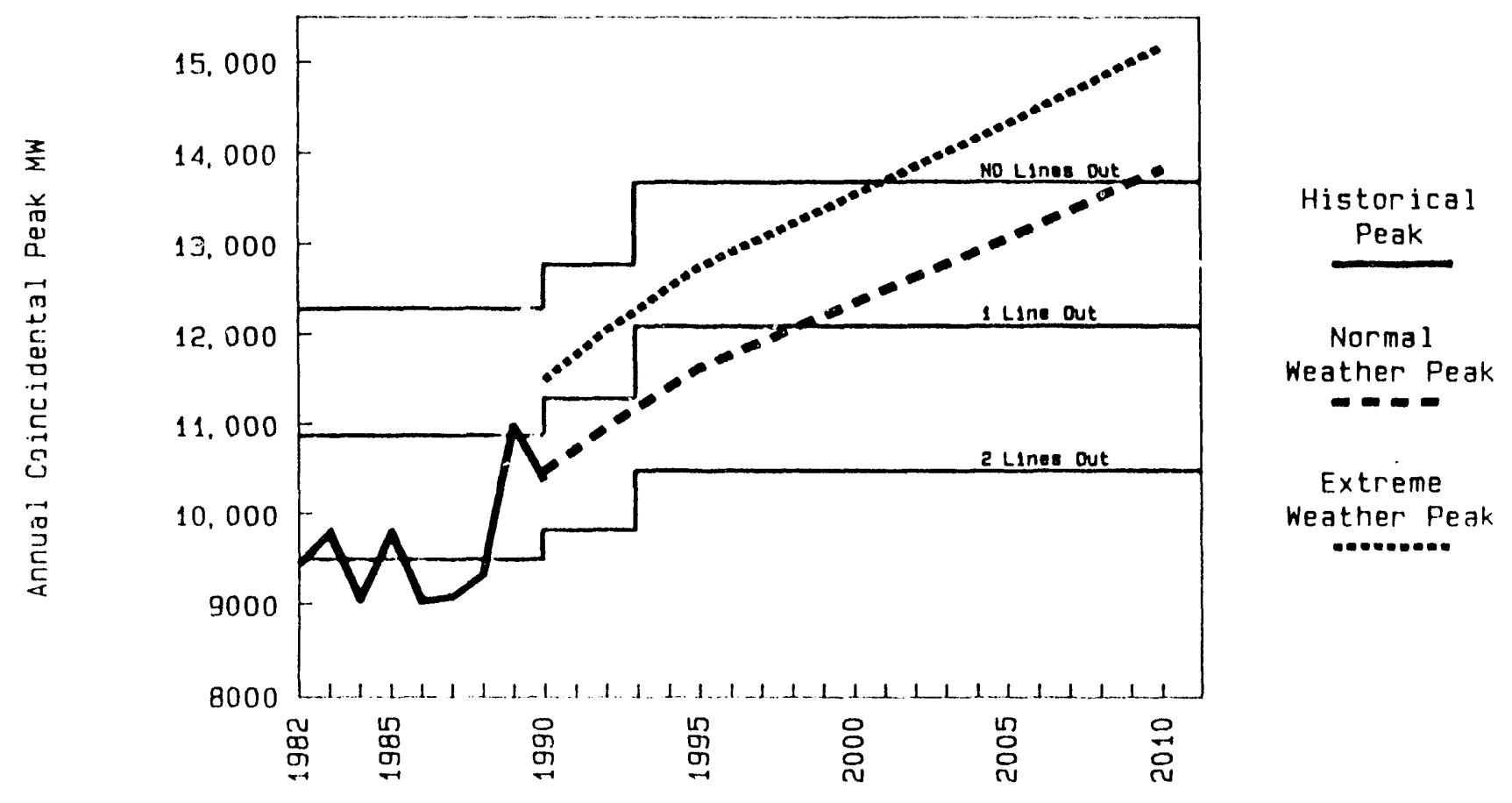

Peak Forecasts are $07 / 07 / 90$

Note: The horizontal lines show estimated Puget Sound area transmission capacity under the conditions indicated. Simplifying assumptions used to produce these lines tend to result in conservative estimates of transmission capacity. System capacity increases between 19901995 reflect voltage support additions by BPA. 
TABLE I I -2

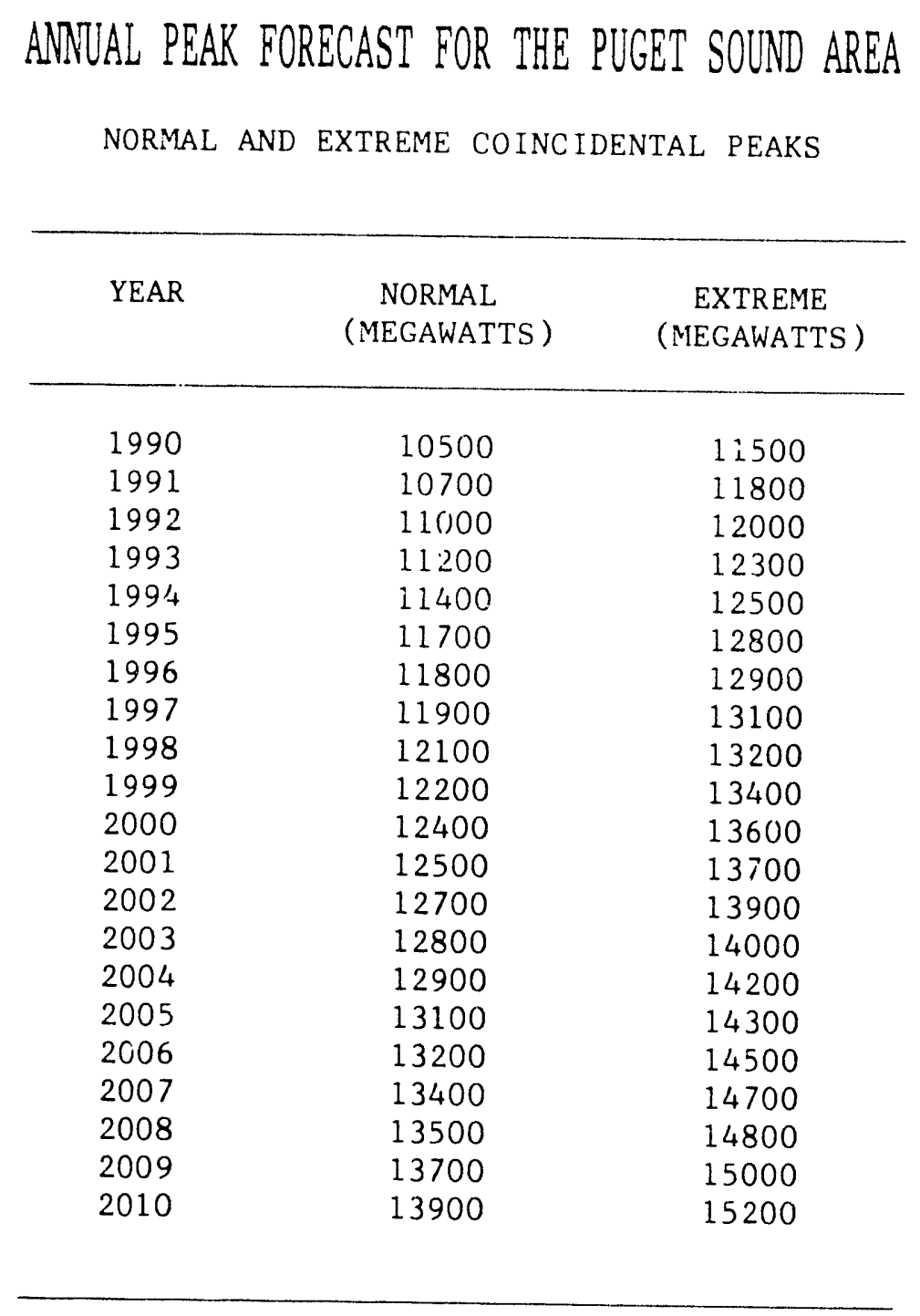


FIGURE II-3

\section{PUGET SCIJND AREA LOAD FORECASTS \\ END USE EXTREME PEAKS, 1990 AND 2010}

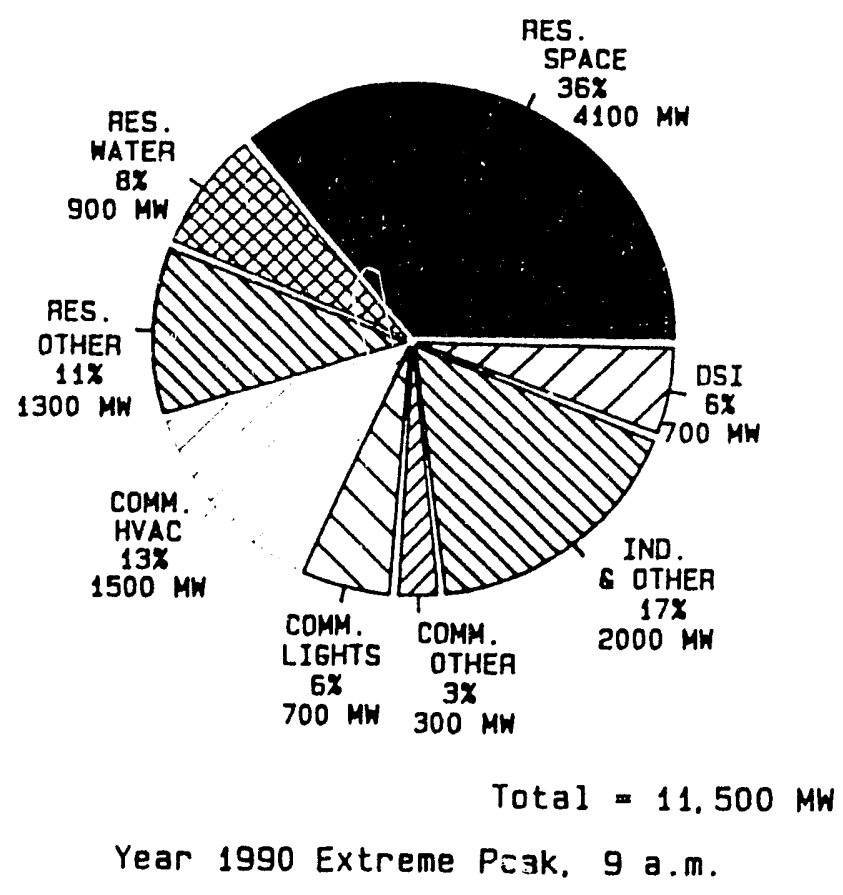

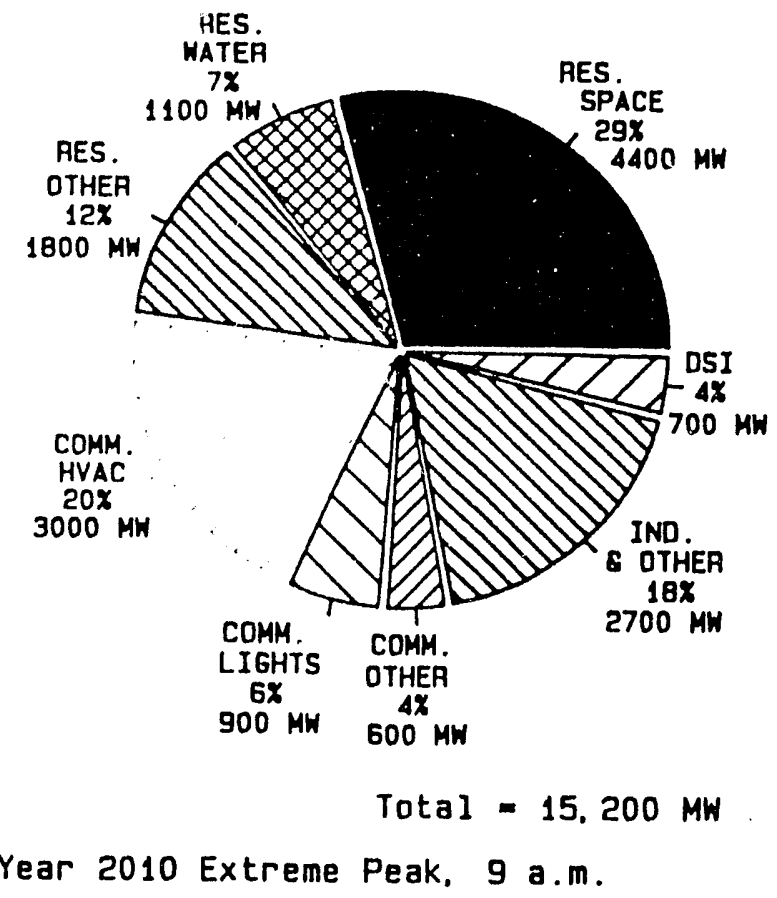




\section{PUGET SOUND AREA LOAD FORECASTS}

END USE NORMAL AND EXTREME PEAKS, 1990

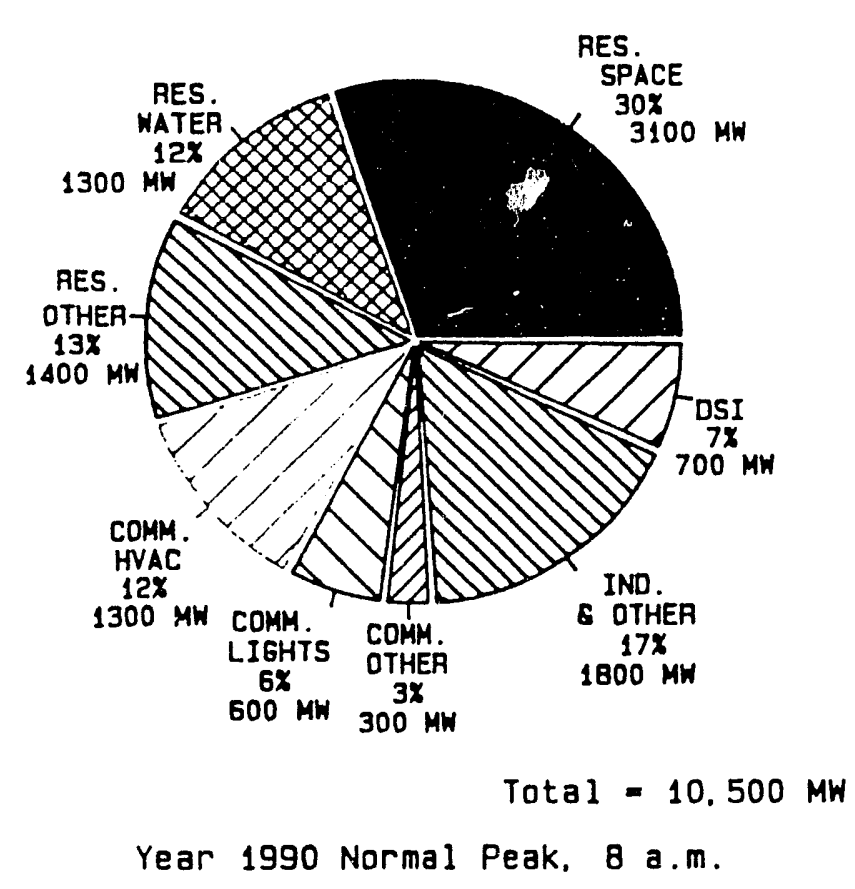

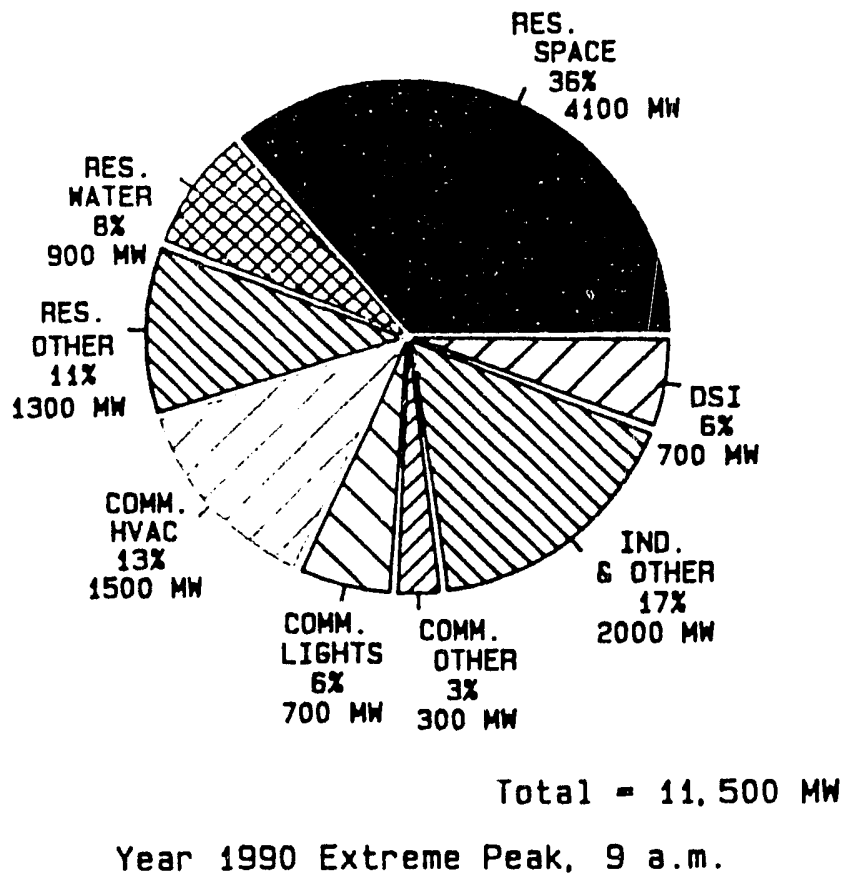


TABLE II-3

\section{LOADS AT TIME OF PEAK BY END-USE}

UNDER NORMAL AND EXTREME WEATHER CONDITIONS

FOR 1990 AND 2010

\begin{tabular}{|c|c|c|c|c|c|c|c|c|}
\hline \multirow{3}{*}{$\begin{array}{l}\text { SECTOR } \\
\text { END-USE }\end{array}$} & \multicolumn{4}{|c|}{1990} & \multicolumn{4}{|c|}{2010} \\
\hline & \multicolumn{2}{|c|}{ NORMAL } & \multicolumn{2}{|c|}{ EXTREME } & \multicolumn{2}{|c|}{ NORMAL } & \multicolumn{2}{|c|}{ EXTREME } \\
\hline & $(\mathrm{MW})$ & $(\%) 1 /$ & (MW) & $(\%) 1 /$ & (MW) & $(\%) 1 /$ & $(\mathrm{MW})$ & (\%) $1 /$ \\
\hline \multicolumn{9}{|l|}{ Residential } \\
\hline Space heat & 3100 & 30 & 4100 & 36 & 3300 & 24 & 4400 & 29 \\
\hline Water heat & 1300 & 12 & 900 & 8 & 1400 & 10 & 1100 & 7 \\
\hline Other & 1400 & 13 & 1300 & 11 & 1800 & 13 & 1800 & 12 \\
\hline \multicolumn{9}{|l|}{ Commercial } \\
\hline HVAC $2 /$ & 1300 & 12 & 1500 & 13 & 2500 & 18 & 3000 & 20 \\
\hline Lighting & 600 & 6 & 700 & 6 & 800 & 6 & 900 & 6 \\
\hline Other & 300 & 3 & 300 & 3 & 600 & 4 & 600 & 4 \\
\hline \multicolumn{9}{|l|}{ Industrial } \\
\hline and other & 1800 & 17 & 2000 & 17 & 2800 & 20 & 2700 & 18 \\
\hline \multirow[t]{2}{*}{ DS I } & 700 & 7 & 700 & 6 & 700 & 5 & 700 & 4 \\
\hline & $====$ & $===$ & $====$ & $===$ & $====$ & $===$ & $====$ & $===$ \\
\hline TOTAL & 10500 & 100 & 11500 & 100 & 13900 & 100 & 15200 & 100 \\
\hline
\end{tabular}

1/ Percent of system total at time of system peak.

2/ Heating, Ventilation and Air Conditioning. 
F IGURE I I -5

\section{ANNUAL FORECAST RAIGES \\ FOR THE PUGET SOLND AREA}

NORMAL PEAKS

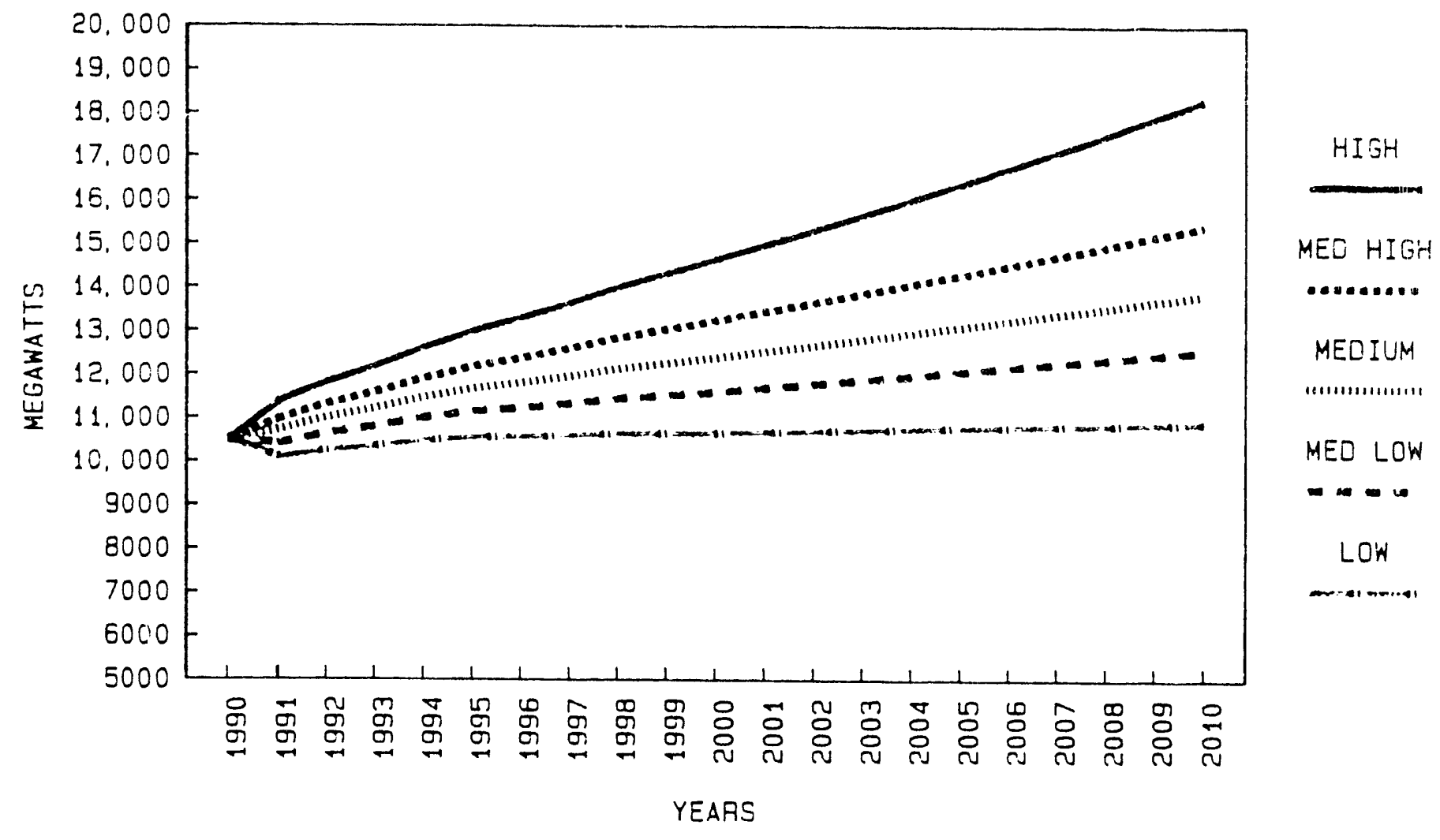


TABLE I I -4

\section{ANNUAL FORECAST RANGES FOR THE PUGET SOUND AREA}

NORMAL PEAKS

(MEGAWATTS )

\begin{tabular}{llllll}
\hline YEAR & HIGH & MEDHI & MEDIUM & MEDLO & LOW \\
$====$ & $=====$ & $====$ & $=====$ & $====$ & $====$ \\
1990 & 10500 & 10500 & 10500 & 10500 & 10500 \\
1991 & 11377 & 10968 & 10706 & 10407 & 10099 \\
1992 & 11820 & 11314 & 10991 & 10642 & 10264 \\
1993 & 12189 & 11585 & 11199 & 10801 & 10354 \\
1994 & 12617 & 11907 & 11455 & 11003 & 10485 \\
1995 & 12991 & 12173 & 11653 & 11150 & 10560 \\
1996 & 13301 & 12374 & 11789 & 11235 & 10577 \\
1997 & 13635 & 12595 & 11941 & 11335 & 10606 \\
1998 & 13998 & 12838 & 12111 & 11451 & 10651 \\
1999 & 14318 & 13037 & 12239 & 11526 & 10656 \\
2000 & 14649 & 13243 & 12372 & 11605 & 10665 \\
2001 & 14979 & 13446 & 12512 & 11699 & 10689 \\
2002 & 15320 & 13656 & 12656 & 11796 & 10716 \\
2003 & 15666 & 13866 & 12799 & 11891 & 10741 \\
2004 & 16020 & 14079 & 12944 & 11987 & 10766 \\
2005 & 16375 & 14290 & 13085 & 12079 & 10787 \\
2006 & 16746 & 14510 & 13233 & 12176 & 10812 \\
2007 & 17117 & 14727 & 13376 & 12268 & 10832 \\
2008 & 17504 & 14952 & 13527 & 12366 & 10856 \\
2009 & 17898 & 15181 & 13678 & 12464 & 10879 \\
2010 & 18298 & 15410 & 13828 & 12560 & 10900 \\
& & & & & \\
\hline
\end{tabular}




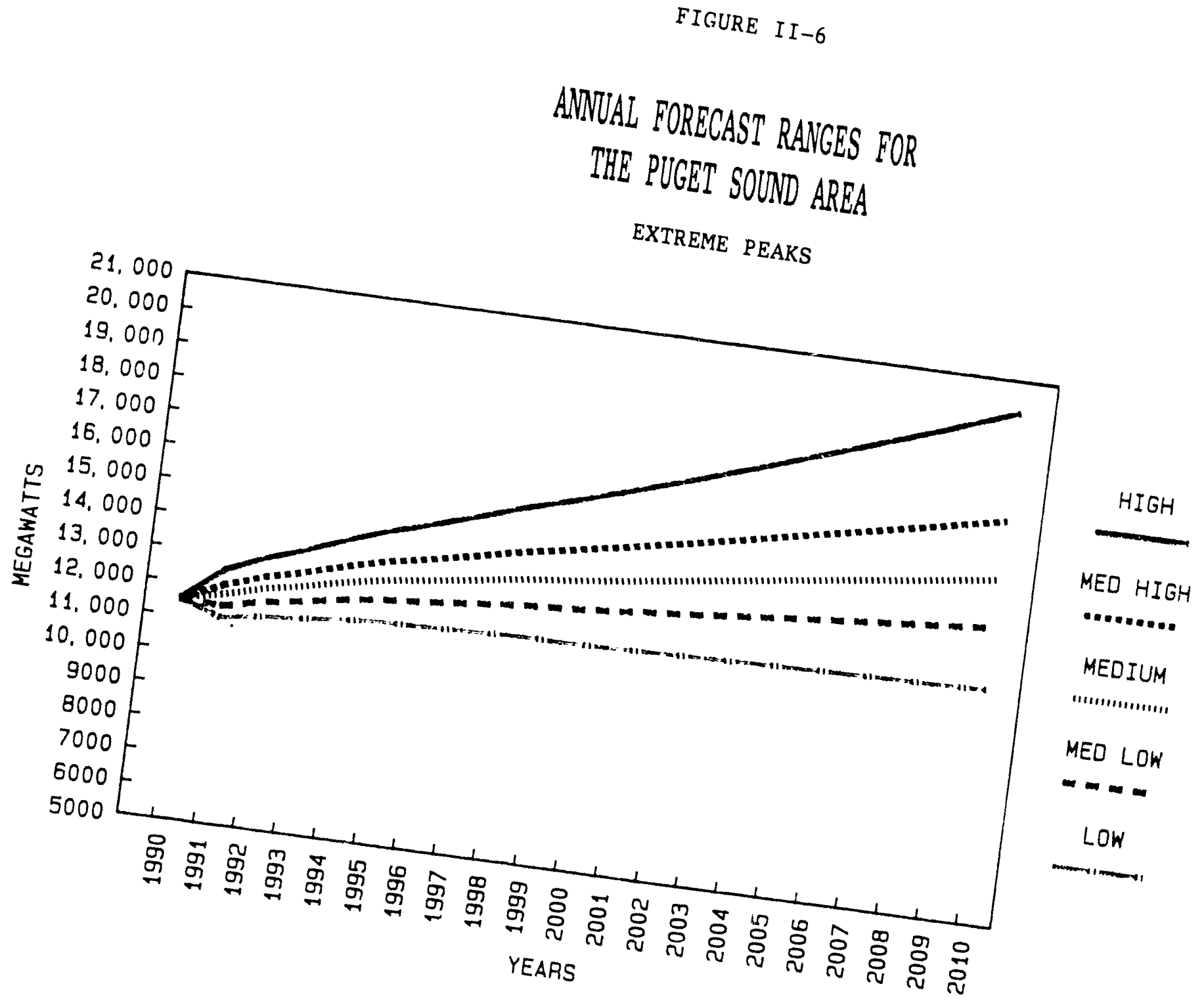


TABLE I I -5

\section{ANNUAL FORECAST RANGES FOR THE PUGET SOUND AREA \\ EXTREME PEAKS \\ (MEGAWATTS )}

\begin{tabular}{|c|c|c|c|c|c|}
\hline YEAR & H IGH & MEDH I & MEDIUM & MEDLO & LOW \\
\hline$====$ & $=== \pm==$ & $====-$ & $=====$ & $=====$ & $=====$ \\
\hline 1990 & 11500 & 11500 & 11500 & 11500 & 11500 \\
\hline 1991 & 12485 & 12033 & 11745 & 11414 & 11074 \\
\hline 1992 & 12976 & 12418 & 12061 & 11675 & 11259 \\
\hline 1993 & 13378 & 12712 & 12286 & 11846 & 11354 \\
\hline 1994 & 13840 & 13056 & 12558 & 12060 & 11488 \\
\hline 1995 & 14245 & 13343 & 12771 & 12216 & 11566 \\
\hline 1996 & 14591 & 13569 & 12924 & 12313 & 11588 \\
\hline 1997 & 14957 & 13810 & 13089 & 12421 & 11618 \\
\hline 1998 & 15356 & 14077 & 13276 & 12548 & 11666 \\
\hline 1999 & 15709 & 14297 & 13418 & 12632 & 11673 \\
\hline 2000 & 16075 & 14526 & 13566 & 12720 & 11683 \\
\hline 2001 & 16442 & 14752 & 13722 & 12825 & 11712 \\
\hline 2002 & 16821 & 14986 & 13883 & 12935 & 11744 \\
\hline 2003 & 17204 & 15219 & 14043 & 13041 & 11773 \\
\hline 2004 & 17598 & 15457 & 14205 & 13149 & 11802 \\
\hline 2005 & 17992 & 15692 & 14362 & 13252 & 11827 \\
\hline 2006 & 18395 & 15930 & 14521 & 13355 & 11851 \\
\hline 2007 & 18798 & 16163 & 14674 & 13453 & 11868 \\
\hline 2008 & 19217 & 16406 & 14834 & 13555 & 11891 \\
\hline 2009 & 19646 & 16652 & 14996 & 13659 & 11912 \\
\hline 2010 & 20079 & 16898 & 15156 & 13760 & 11932 \\
\hline
\end{tabular}




\section{PUGET SOUND AREA POWER SYSTEM CAPACITY}

Introduction. Reliable performance of the power system serving Puget Sound requires that system capacity be equal to or greater than peak power demand. Chapter II defined present and future peak power demand that the system must serve. This chapter defines system capacity and discusses how it is determined through technical studies.

BPA and the other Puget Sound utilities establish minimum performance standards for the power system in the form of reliability criteria. The BPA Reliability Criteria establish the minimum performance requirements that are used in planning, designing, operating and maintaining the main grid bulk power system. System capacity is defined in terms of these criteria as the maximum load that can be served without violating performance criteria requirements.

System capacity is determined by conducting computer simulations of system performance for the various disturbances spelled out in the criteria. The capacity of the existing Puget Sound system is indicated in Figure II-2 by the horizontal dashed lines. These values represent the load levels at which there is insufficient reactive reserve or margin to prevent voltage collapse.

Definitions. The following terms are used in throughout this report. A brief explanation of these terms is provided to aid in understanding the transmission system issues facing the Puget Sound area.

Reactive Power. Electric and magnetic fields are the medium by which electrical power is generated, transmitted, and converted to useful work. All elements of the power system including generators, transmission lines, transformers, and motors rely on electric and magnetic fields to perform their function. Electric fields are associated with voltage while magnetic fields are associated with current. These fields store significant amounts of electrical power. In an alternating current ( $A C$ ) system, voltage and currents alternate between zero and peak 120 times per second (twice each $60 \mathrm{~Hz}$ cycle). Correspondingly, power goes in and out of the myriad magnetic and electric fields at the same rate. However, no power is consumed; it is only moved from one place to another much like moving funds between accounts in a bank.

This flow of power in and out of storage in magnetic and electric fields is called reactive power. Devices such as motors that function predominantly through magnetic fields are said to consume reactive power while devices that function through electric fields such as capacitor banks are said to produce reactive power. Transmission 1 ines, which function both through magnetic and electric fields, can be either a reactive power consumer or a reactive producer depending on how heavily loaded they are. When ines are heavily loaded the magnetic field dominates and the line consumes reactive power. Under light load the electric field dominates and the line produces reactive power. 
These production and consumption labels are purely a convention to account for the fact that some devices are discharging stored field power as others are absorbing it. At any given moment, the reactive power produced and consumed in the power system must be in balance.

Voltage Collapse. This reactive power balance is necessary for stable voltage on a power system. If more reactive power is being produced than corsumed, voltage will rise, whereas a deficit of reactive power will cause voltage to drop. Generators are extremely important in maintaining the balance of reactive power necessary for stable voltage. A generator can either produce or consume reactive power depending on the setting of its field winding excitation control. Generator exciters constantly monitor system voltage. If voltage starts to sag, the exciter automatically increases field current causing reactive power injection into the system to counteract the sag. On the other hand, if voltage rises, the exr.j.ter reduces field current to absorb reactive power.

In major load centers fed by long transmission lines, capacitor banks are used to supply reactive power during periods of heavy load. The capacitor banks are switched on when voltage sags as a result of reactive power consumption by the heavily loaded lines. Capacitor banks are good inexpensive sources of reactive power and perform well if voltage is fairly steady. However, if system voltage drops, their reactive power output goes down by the square of the voltage drop. Unlike generators, capacitor banks are inherentlya destabilizing force in reactive power dynamics. A further destabilizing effect is that, as voltage drops, current flows increase in transmission lines react to maintain constant power. The reactive power consumption of the lines increases by the square of the current, driving voltage down further.

The stabilizing force of generators counteracts this process and restores reactive power balance maintaining stable voltage. But generators have limited reactive power capacity, and their exciters will limit reactive power output to protect the generator. Moreover, only the generators near the load center are effective at stabilizing voltage because long, heavily loaded transmission 1 ines cannot transport reactive power from remote generators.

During heavy peak load, occurrence of a major disturbance, such as loss of a critical line, causes an increase in reactive power consumption, and voltages drop. Generators in the load area automatically adjust reactive output to restore balance but quickly reach their capacity limits. Once this point is reached there is no stabilizing force to counteract the destabilizing response of the capacitor banks, and voltage drops to either a sustained extreme low voltage condition or a cascading total loss of load.

Brownout. Outage of a major facility such as a generator or 1 ine may cause a reactive power deficit. The power system may reach an operating point where voltages are severely depressed yet the system stays intact. This is called a brownout. The low voltage may damage some loads such as motors. Other loads such as computers may malfunction while some loads are likely to disconnect for self protection. 
Blackout. System voltages may drop far enough so that protective relays misinterpret the conditicn as a line fault and disconnect a transmission line. This will cause voltages to drop further causing more lines to disconnect in cascading fashion. Ultimately loads are totally disconnected from generation, and the system goes black.

Reliability Criteria. As discussed earlier, the BPA Reliability Criteria set standards for planning, designing, operating and maintaining the transmission system to insure cost-effective reliability of service. Cost-effectiveness is viewed from the perspective of the electricity consumer. The system is planned to have sufficient strength or capacity to maintain continuity and quality of service to electrical loads during certain more commun

contingencies or system disturbances. For other less common contingencies, it is not economical to provide enough capacity to maintain full service, so interruption of service or some reduction of quality of service is allowed.

The performance requirements of the criteria that pertain to the main grid transmission system are summarized in Table III-1. The first section of the table lists contingencies in order of decreasing likelihood and specifies the performance level the system must meet for the particular contingency. The second section defines each of the performance levels in terms of load served, voltage requirements and overloads of facilities.

Transmission Modeling. The severity and extent of the peak load capacity problem in the Puget Sound area can be determined by computer simulation scudies that model the response of the power system to various critical disturbances specified in the Reliability Crite:-ia. Planning data from utilities throughout the Western United States and Canada are used to project load levels, available generation and transmission network configurations at various points in the future as far out as 20 years. Base cases, which are the detailed technical data bases required by the modeling programs, are developed from this planning information for the future years to b? studied. Within a given study year there are typically a number of variations set up to represent seasonal load and generation patterns. Initial studies have shown that the critical outage cases for Puget Sound voltage stability are:

- Outage of the Chief Joseph - Monroe 500-iv line during an abnormal winter peak.

- Outage of both circuits of the Coulee-Raver double--circuit 500-kV line during a normal winter peak.

- Outage of the Trojan generator with one of the Centralia generators already out of service during an abnormal winter peak.

In the fall of 1988 , BPA system planners, while conducting routine studies of future Puget Sound voltage support needs, discovered the first signs that there could be a serious voltage stability problem in the Puget Sound area. Small changes in study assumptions produced wide variations in results ard many cases would not converge (arrive at a solution in the computer model) or converged at extremely low voltages.

Further in-depth siudies were made using a new methodology, referrer to as the post-transient method, developed to study voltage stability problems on the AC intertie. These studies revealed that for certain critical line or generator 


\section{MAIN GRID DISTURBANCE/PERFORMANCE TABLE}

\section{DISTURBANCE-PERFORMANCE TABLE}

CONTINGENCY (ELEMENTS LOST)

(independent unless otherwise noted) none (system normal)

\begin{tabular}{ll}
\hline one generator & B \\
\hline $\begin{array}{l}\text { one transformer, or } \\
\text { two generators, or } \\
\text { one line }\end{array}$ & $\mathrm{D}$ \\
\hline $\begin{array}{l}\text { one generator + one transformer, or } \\
\text { one line + one generator, or } \\
\text { stuck breaker or bus, or } \\
\text { two lines (common row, bus, or PCB) } \star\end{array}$ & $\mathrm{E}$ \\
\hline $\begin{array}{l}\text { two transformers, or } \\
\text { one line }+ \text { one transformer }\end{array}$ & $\mathrm{G}$ \\
\hline $\begin{array}{l}\text { two lines, or } \\
\text { three or more lines in a pass or corridor } \star\end{array}$ & \\
\hline
\end{tabular}

PERFORMANCE

LEVEL REQUIRED

A

B

.


outages during extreme winter peak loads the Puget Sound area did not have enough reactive margin to prevent voltage collapse. In the spring of 1989 , studies representing system conditions that ocurred during the severe February cold spell showed that loss of one of the $500-\mathrm{kV}$ cross-Cascade transmission lines could have caused voltage collapse and widespread loss of load over the entire Puget Sound area.

Post-Transient Method. The time line of events following a major system disturbance such as loss of a transmission line or large generator can be divided into three distinct periods. In the first 1-2 minutes following the disturbance, automatic control systems resfond to counteract power oscillations and imbalances that could otherwise cause system breakup. This is called the transient period. Examples of these automatic actions include disconnecting a faulted transmission line, action by generator controls to maintain constant frequency and terminal voltage or automatic disconnecting of interruptible loads. At the other end of the time line, approximately 10-15 minutes after the disturbance, system operators have had sufficient time to assess the state of the system and to begin taking manual control actions to readjust the system. Such actions might include switching on capacitor banks, changing voltage taps on main grid transformers or sending orders to generating plants to reschedule generation levels. This period is commonly referred to as the steady-state period.

The intermediate period after automatic control actions have taken place, but before system operators have had time to readjust the system, is known as the post-transient period. It is during this period that the system is most vulnerable to voltage collapse. In the past system planners assumed that if the system survived the transient period, then it would stay intact long enough for system operators to respond during the steady-state period. Transient stability studies modeled system performance during the transient period to determine if the system would survive the initial disturbance. Power flow studies examined the performance of the system during the steady-state period to determine if voltages and line loadings were within limits after system operator response.

In the last $\mathrm{few}$ years, however, the utility industry has become increasingly concerned about the performance of power systems during the post-transient period. Financial pressures on utilities have led them to operate their systems ever closer to capacity limits to defer major investments in new facilities. Blackouts of major load centers in Japan, France, Canada and the U.S. caused by voltage collapse during the post-transient period have occurred since 1985. System planners can no longer assume that the system is inherently secure during the post-transient period. Planning studies must consider the vulnerability to voltage collapse during this period.

There are no totally adequate computer models to simulate power system response during the post-transient period. Substantial utility R\&D resources have been committed to developing extended term dynanics models that will extend the capability of traditional transient stability programs to model system performance during the post-transient period. However, production grade versions of these computer models currently under development will not be available to system planners before the end of 1990. In late 1988, 
compelled by the need to investigate the emerging voltage collapse threat in the Puget Sound area, BPA developed an interim study methodology that allowed using the conventional power flow model to analyze post-transient voltage collapse. The essence of this "post-transient method" entailed modification of the power flow program to block all system adjustments that require human intervention, cnly allowing automatic adjustments to occur in the model. The Puget Sound voltage stability studies including determinations of present and future system capacity have been based on this methodology.

$\mathrm{Q}-\mathrm{V}$ and $\mathrm{P}-\mathrm{V}$ Analysis. $\mathrm{Q}-\mathrm{V}$ (Reactive Power verses Voltage) and $\mathrm{P}-\mathrm{V}$ (Real Power verses Voltage) analysis are techniques used as part of the post-transient methodology to determine how the system will respond to changes in real and reactive power flows and the vulnerability to voltage collapse.

A Q-V curve describes the relationship between voltage at a particular bus in the system and reactive power injection into the bus. A unique Q-V curve exists for each bus in the system for a given system state (loads, generation and network condition). A Q-V curve is generated by running series of power flow studies varying bus voltage incrementally over the range of interest to determine the reactive power injection required at each successive voltage level. Figure III-1 shows a typical Q-V curve for two different system states, system normal and after an outage of a line. The point at which the slope of the curve goes from positive to negative is called the point of instability. The horizontal distance from the instability point to the operating point is called the reactive margin. Normally the operating point is determined by the point of zero reactive injection. However if the bus has a reactive power source such as a capacitor bank connected to it, the operating point will be determined by the reactive power output of the capacitor bank. Determining systen capacity for a given state of the transmission system entails generating $Q-V$ curves at a number of critical buses for successively increasing loads to find the point where there is insufficient reactive margin above the point of instability.

$P-V$ analysis is very similar to $Q-V$ analysis except that $P-V$ analysis looks at bus voltage response to variations in total real power load over the whole load area. Voltage stability studies rely principally on $Q-V$ analysis with $P-V$ analysis providing a consistency check. Much valuable qualitative information can be determined from the shape of the $Q-V$ and $P-V$ curves. For example a steep slopped curve means the system is in a state of high stress where small variations in system conditions will cause wide swings in system voltage.

Load Modeling. Properly representing how loads respond to voltage changes is the most formidable challenge in voltage stability studies. Reasonably good models of different types of loads have been developed and verified through EPRI sponsored research. It would be a fairly strajght forward task to model a simple power system with a few known load types. However, it quickly becomes a task of enormous proportions for a system as extensive and diverse as that serving the Puget Sound area composed of hundreds of transmission lines, feeding thousands of distribution circuits connecting many millions of end-use loads each of which has unique daily and seasonal use patterns. 
FIGURE III-1

TYPICAL Q-V CURVES

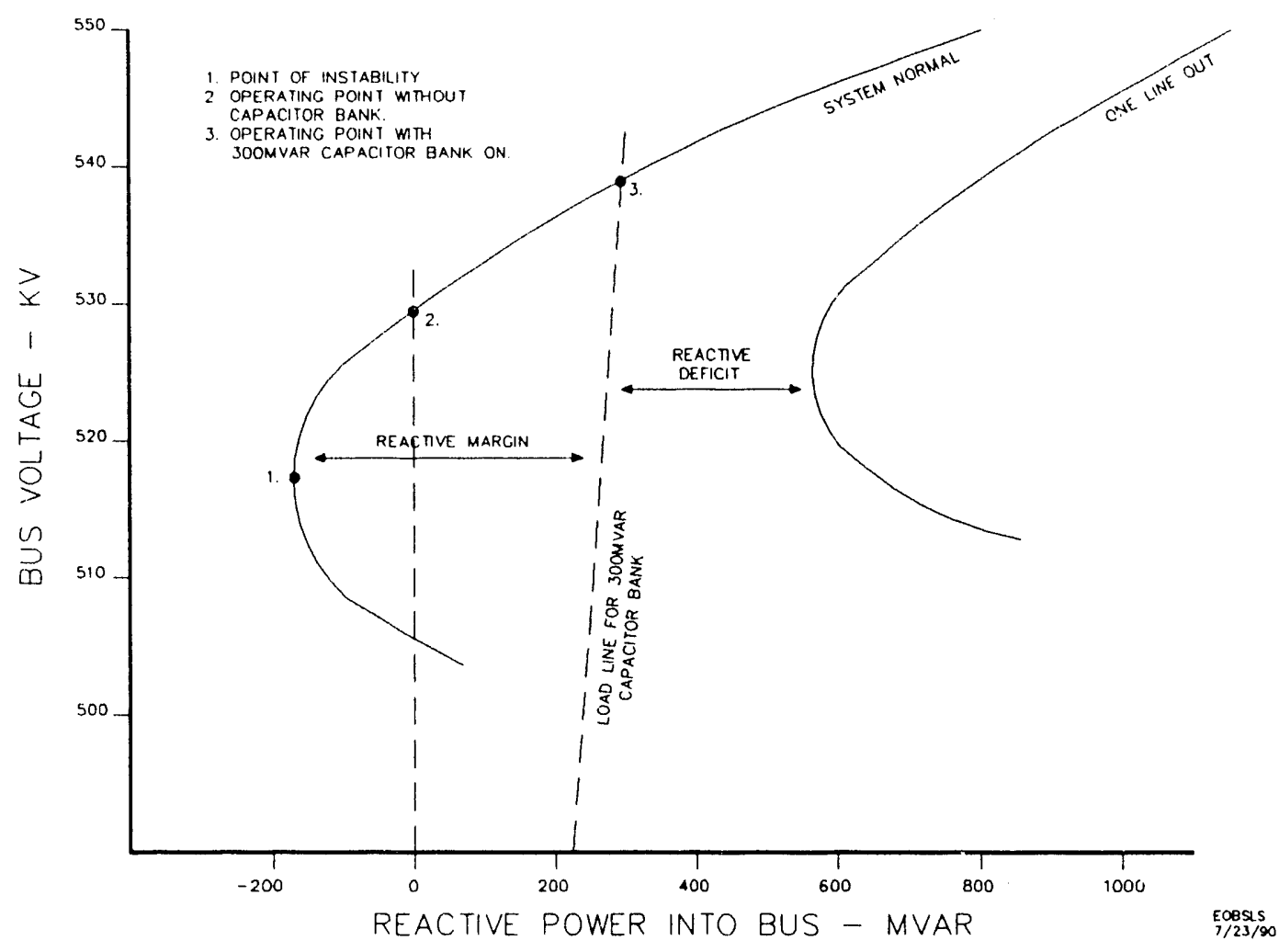

TYPICAL P-V CURVES

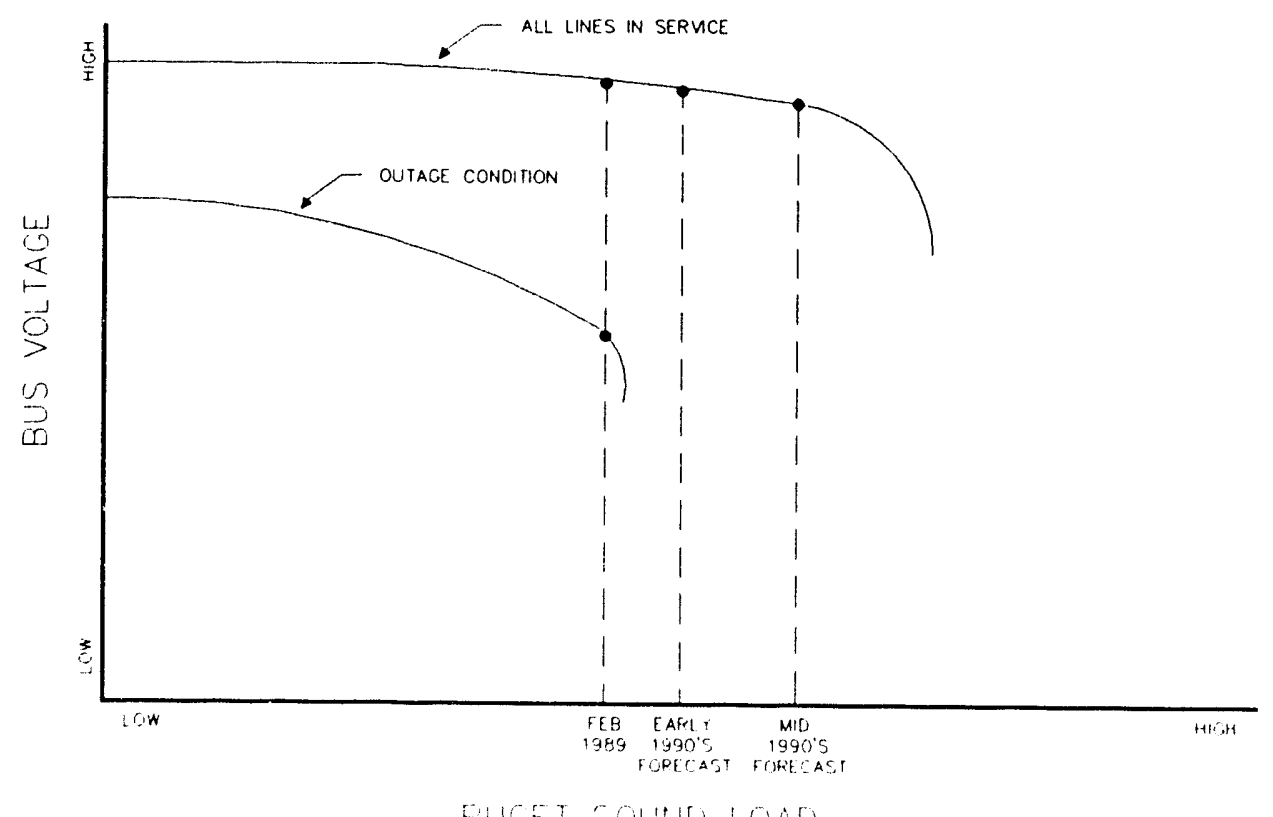

Fuget SOUHU loAD 
Fortunately methods are available to greatly simplify the task by representing a distribution feeder and all the connected loads as a single element with approximately equivalent response. This equivalent load is composed of three components in varying proportion:

- Constant power - no variation with voltage change

- Constant current - varies linearly with voltage change

o Constant impedance - varies as the square of the voltage

Some loads types are predominantly one component. Resistive space heating, a major factor for winter peak loads, is all constant impedance. Motor loads tend to be mostly constant power. An EPRI developed r.rogram called LOADSYN has become a utility standard tool for determining equivalent load models. Given data on sector mix (commercial, residential, etc) for a particular distribution feeder and data on typical load compos:tion (resistance space heating, fluorescent lighting, motor type, etc), LOADEYN will calculate a single equivalent load model for the circuit.

The voltage stability studies up to this point have assumed that all loads are constant power. This is generally a conservative assumption that will produce "safe" results that underestimate actual systern capacity. Transmission and Load Forecasting study teams have been working together over the last 9 months collecting detailed load data from Puget Sound and Portland area utilities to develop LOADSYN equivalent load models for all load buses in the Puget Sound and Portland area. These models should be completed and load response studies underway by early August.

Interpreting the results of load response studies will have to be done very judiciously because of the uncertainty in the data used to construct the load models. Most utilities do not have detailed data on load characteristics at each load bus and developing this level of detailed load data would be prohibitively expensive. The quality of data avajlable varies from good to essentially an educated guess. Sanity checks of the load data are being made by comparing load class totals by utility against independently developed regional load composition data.

Another source of uncertainty in the load models is the effect of thermostat controls on resistive heat load. As voltage drops there is a significant immediate reduction in resistance space heat, water heat and cooking loads. Thermostats controlling these loads will try to counteract this loss of heat output resulting in an aggregate loss of load diversity for these loads. This effect could substantially reduce the apparent load relief that would otherwise result from voltage drop. How to account for this effect in load response studies has not yet been adequately resolved.

Until such time that more reliable load data can be developed, baseline voltage stability studies and system capacity determinations will continue to rely on constant power load models. Load response studies will be used to test the sensitivity of results to load assumptions. In addition, utilities will be conducting field tests to measure the actual response of the system to voltage changes. 
Network Model. System models used in power flow studies represent the entire electrical network of the Western Systems Coordinating Council (WSCC) which covers ten western states and British Columbia and Alberta. To reduce the computational burden for Northwest regional studies, much of the detail outside the Northwest is reduced to simplified equivalent networks. Much of the subtransmission network at $115-\mathrm{kV}$ and below within the Northwest is alio reduced for conventional power flow studies of main grid performance.

Reactive losses in the Puget Sound subtransmission network could adversely affect voltage stability, yet are not fully accounted for in these reduced models. Because of this and the need to facilitate the detailed load model work discussed above, the Transmission Study Team is developing "super base cases" combining detailed network models from all the Puget Sound utilities plus lower British Columbia and the Portland area. This extended model also represents automatic voltage regulating transformers and more detailed models of local generation exciter response.

The super base case including detailed load models is being developed initially for 1993 studies and will later be extended to 1997. Super base cases with constant power loads are being developed for 1993, 1997, 2000 and 2004 studies. All future voltage stability studies will use these super base case models.

Study Assumptions. The following basic assumptions were used in Phase I studies to assess the performance of the transmission system under a variety of simulated conditions. Assumptions will be revised in future studies as needed to reflect changes in near term utility resource and transmission plans and refined technical information.

Resource Assumptions

1. Puget Sound area hydro generation performs at median water firm. Winter peaking levels prior to January 6 (reduced Skagit River generation.) Snoqualmie Falls frozen with no generation during abnormal cold.

2. PSP\&L combustion turbines will be generating during abnormal cold except Whitehorn unit $\mathbb{k}_{3} 3$ and Shuffleton units are of $f$.

3. PSP\&L combustion turbines are off during normal winter peak load.

4. PGE's Beaver combustion turbine/combined cycle plant is off.

5. Coulee serves as a baseload generator with 4500 NW generation.

6. Snake River projects provide peaking generation.

Intertie Schedules

7. B.C. Hydro to Pacific Northwest (BCH-PNW) schedule is 250 MW during normal and abnormal cold. After the $B C H$ to Washington Water Power (WWP) intertie is completed in the mid 1990s, total BCH-PNW schedule will be $850 \mathrm{MW}$. Phase shifters on the eastern BCH system will cause 600 MW to flow directly to WWP. The Nelway phase shifter will be adjusted to minimize inadvertent flow, assuring Ingledow to Custer power flow will consistently be about 250 MW. 
8. $\mathrm{BCH}$ is using two Burrard units as synchronous condensers for normal and and four units for abnormal winter loads. Zero reactive is generated prior to a contingency.

9. PNW-PSW interchange is zero during abnormal cold if PNW resources are sufficient to meet the cold weather load.

10. PNW imports from the PSW on the DC intertie if PNW resources are insufficient to meet the assumed cold weather load.

11. PNW-PSW interchange during normal peak is 1000 MW DC and 2000 MW AC export to PSW in 1996. Export in later years decreases to allow PNW resources to meet the assumed normal load.

12. Canadian Entitlement return will not be included in base cases. Sensitivity studies will assess the Puget Sound voltage stability impacts for a range of capacity schedules (up to $1400 \mathrm{MW}$ ) to Canada during winter peak loads.

System Design

13. The operating point will be planned to provide 500 MVAR shunt reactive margin from the voltage instability point.

14. The newly revised Reliability Criteria are applied. (See Table III-1)

15. The system will be designed to restore full load immediately following the contingency unless a detailed system study shows the load cannot be fully restored with a 95 percent voltage level at BPA delivery points. The system will not be designed to use the direct load trip scheme now installed at Intalco and Kaiser.

Load Level Assumptions

16. The normal and extreme winter peak load forecasts displayed in Table II-2, are assumed for transmission studies. Sensitivity to load growth assumptions will be tested using the loads from Table II- 4 and II-5. The power factor for abnormal is the same as normal weather.

System Addition Assumptions

Prior to Winter 1992-1993:

Raver 500-kV shunt capacitors (brings total to 952 MVAR)

Columbia series capacitor upgrade ( $2400 \mathrm{~A}, 22.5$ percent)

Olympia-Port Angeles 230-kV loop-in at Shelton

Shelton-Port Angeles 230-kV loop-in at Fairmount

Port Angeles $115-\mathrm{kV}$ terminals in advance of added Daishowa load

(assumed schedule: phase 1 - fall 1993, phase 2 - fall 1995)

01ympia 230-kV shunt capacitors (2-150 MVAR banks, remove old 100 MVAR bank) Custer-Bellingham $230-\mathrm{kV}$ 非 2 line

$\mathrm{BCH}$ Nelway phase shifter

$\mathrm{BCH}$ Nicola-Meridian series capacitors (50 percent)

$\mathrm{BCH}$ Nicola-Ingledow series capacitors (50 percent)

TCL shunt capacitors at Southwest (100 MVAR), Pearl (60 MVAR), Northeast (80 MVAR) and Cowlitz (60 MVAR) 
Prior to Winter 1995-1996:

Cowlitz-0lympia 230-kV line

Cowlitz Falls Integration (Mayfield-Mossyrock 230-kV 1oop-in)

Port Angeles 115-kV shunt capacitors (Daishowa phase 1, 2-23.7 MVAR banks)

Shelton 230-kV shunt capacitors (Daishowa phase 1, 1-114 MVAR bank)

Fairmount-Port Angeles 230-kV 1ine (3rd 1ine, Daishowa phase 1)

She1ton-Fairmount 230-kV line (3rd 1ine, Daishowa phase 2)

Olympic Peninsula Reinforcement with 500-kV to Shelton

A11ston 500/230-kV transformer 非 2

Ostrander 500-kV shunt capacitors (1-312 MVAR bank)

Keeler 500-kV shunt capacitors (1-312 MVAR bank)

$\mathrm{BCH}$ Williston-Kelly Lake 500-kV 非 1 ine with series capacitors

$\mathrm{BCH}$ Kelly Lake-Cheekye 500-kV 非 1 ine with series capacitors

BCH Ingledow static var device (150 MVAR)

BCH-WWP intertie ( $600 \mathrm{MW}$ added import assumed for both normal and abnormal)

Prior to Winter 2003-2004:

No assumed additions after 1996. 
IV. MEASURE CATEGORIES

Introduction. This chapter describes the results of the scoping process in each of the four measure categories: conservation \& load management, local generation, transmission, and load curtailment. It begins with a description of the screening criteria that were applied to measures within each category. Separate sections for each of the measure categories list all options identified and describe in more detail the measures that passed the initial screening process. These are the measures that the study teams propose for use when developing alternative strategies in Phase II of the study. The descriptions include estimates of cost, quantity, and availability for each measure.

Screening Criteria. The evaluation team developed screening criteria for the study teams to assess which measures merit further analysis. These criteria were used as rough guidelines for the teams to consider when deciding which components of the measure categories to include in their lists. The screening criteria were not considered as absolute; judgment complemented the criteria where appropriate.

Table IV-1 lists the screening criteria. These criteria received public review at the March technical review group meeting. 


\section{SCREENING CRITERIA}

\section{Market Factors}

Commercially Available Technology

Commercially Proven Technology/ Confirmed Resource

Acceptable to the Market

\section{Resource Characteristics}

On-1ine date no later than 1999

Available during cold weather from November through March

Located within the Puget Sound area

Costs should be reasonable relative to the estimated cost of

transmission (approximately $\$ 100$ per $\mathrm{kW}$ ), the estimated cost of a single cycle combustion turbine (approximately $\$ 650$ per $\mathrm{kW}$ ), and the regional cost-effectiveness limit of 50 mills per kWh

\section{Environmental Criteria}

Meets state and federal environmental quality laws and standards (e.g., air quality standards, water quality standards, etc.)

Avoids protected sites and environmentally unique habitats (e.g., the Council's Protected Areas, wetlands, national parks, etc.) 


\section{A. CONSERVATION \& LOAD MANAGEMENT}

Background. Sonservation and load management are frequently referred to as demand-side management. These types of actions may be designed to influence. customer use of electricity in ways that would reduce the peak load stress on the transmission system in the Puget Sound area. The types of demand-side management actions are illustrated in Figure IV-A-1. Of these actions, conservation and load shifting were emphasized in this analysis.

Utilities in the Pacific Northwest are more familiar with conservation than with load management for satisfying the requirements of growing loads. Conservation is defined as the more efficient use of electricity in any of the consuming sectors: residential, commercial, industrial, or irrigation. As illustrated in Figure IV-A-1, conservation typically reduces the level of electricity use at all hours of the day, and therefore can help reduce transmission requirements.

Load management is the demand side option most frequently associated with peak load problems. It is also the area with which utilities in the Pacific Northwest have the least experience, since the Pacific Northwest generating system is energy-constrained and not capacity constrained. Utilities in this part of the country typically have few problems meeting peak demand. Load management emphasizes the management of electricity use during a day (i.e., rescheduling some uses for other than peak times). This is illustrated in Figure IV-A-1 where electricity use during peak hours is shifted to off-peak hours. Load management does not typically reduce overall electricity use. As with conservation, load management can be applied to all sectors.

Conservation \& Load Management Options. The conservation and load management team's first task was to develop a list of conservation and load management options which may have the potential to reduce Puget Sound area ptak loads on an average and extremely cold winter day. The identification of these options was based on the team's understanding of the peak load problem and level of knowledge about various demand-side management program impacts. The 1 ist of potential options was reviewed with the technical review group and was refined several times. The screening criteria described earlier in this chapter were used as guidelines for selection of options. Around 20 options were considered for analysis. The options that passed the screening are shown in Table IV-A-1. Those not recommended for further analysis are listed in Table IV-A-2.

Methodology. The team estimated the maximum achievable peak reduction potential in the Puget Sound area: conservation beyond what is currently planned, load management options, and each option's associated costs. Estimates were developed for a normal winter peak day as well as an extreme winter peak day. System load shape impacts were projected for both day types.

The estimates of conservation and load management potential were developed using the same methods that were used to develop the estimates of conservation 


\section{DEMAND-SIDE MANGGEMENT}

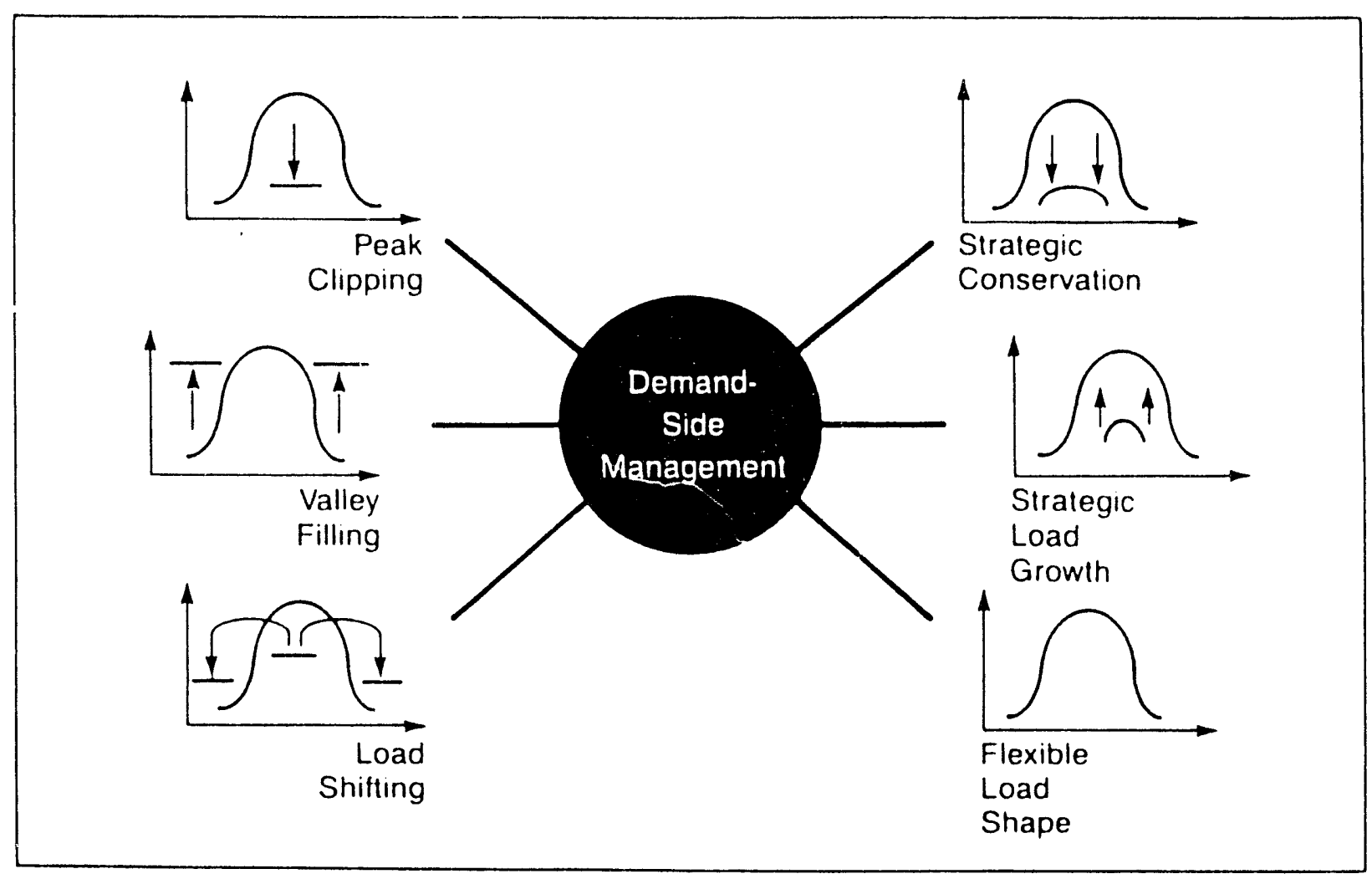

Source: Electric Power Research Institute 
TABLE IV-A-1

\section{CONSERVATION AND LOAD MANAGEMENT OPTIONS THAT REMAIN AFTER INITIAL SCREENING \\ BY SECTOR}

\begin{tabular}{|c|c|c|c|}
\hline SECTOR & CONSERVATION & $\begin{array}{l}\text { LOAD } \\
\text { MANAGEMENT }\end{array}$ & OTHER \\
\hline Residential & $\begin{array}{l}\text { Weatherization I/ } \\
\text { Low flow shower } \\
\text { heads }\end{array}$ & $\begin{array}{l}\text { Space heat controls } \\
\text { Water heater package } 4 / \\
\text { Whole house demand control } \\
\text { Thermal heat shortage } \\
\text { Time-of-Use (TOU) rates }\end{array}$ & Fuel switching \\
\hline Commercial & $\begin{array}{l}\text { Existing } 2 / \\
\text { New } \underline{2} /\end{array}$ & & 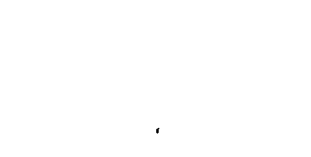 \\
\hline Industrial & $\begin{array}{c}\text { Energy Savings } \mathrm{Plan} \\
\text { conservation } 3 /\end{array}$ & & \\
\hline
\end{tabular}

1/ Includes insulation; water heater wraps; double or triple pane windows; more efficient water heaters.

2/ Includes insulation; efficient lights, HVAC systems and refrigeration.

$3 /$ Includes lighting, HVAC, process heating, pumping, compressed air, motors.

$4 /$ Includes water heater controls, low flow shower heads, and larger, more efficient tanks. 
TABLE IV-A-2

\section{OPTIONS DELETED FROM CONSIDERATION BY \\ INITIAL SCREENING \\ BY SECTOR}

\begin{tabular}{|c|c|c|}
\hline SECTOR & OPTION & REASON FOR SCREENING \\
\hline Residen: $:$ al & Space heat set-back controls & May increase peak \\
\hline Residential & Water heater replacement & Limited peak reduction \\
\hline Residential & Lighting effic. and controls & Limited peak reduction \\
\hline Residential & Solar augmntn. for water heaters & Appears unreliable \\
\hline Residential & Gas back-up for heat pumps & Expensive \\
\hline Residential & Portable gas generators & Environmental issues \\
\hline Commercial & Lighting controls & Incl in commercial conservation \\
\hline Commercial & Street lighting efficiency & Affects off-peak load \\
\hline Commercial & Whole building controls & considered as load curtailment \\
\hline Comm \& Ind 1 & Dual fuel boilers & Limited potential \\
\hline Comm \& Ind 1 & Fuel switching & Limited potential \\
\hline Comm \& Ind 1 & TOU rates & Can increase energy use \\
\hline Conm \& Ind 1 & Interruptible rates & Considered as load curtailment \\
\hline
\end{tabular}


supply for BPA's 1990 Resource Program and the Northwest Power Planning Council's 1990 Power Plan. These methods were developed during extensive public involvement processes and are the result of consensus among experts in the region. In addition, the data used for assessing conservation potential have also been reviewed by a regional panel. The methods and data used for the conservation analysis are described in BPA's draft 1990 Conservation Resources Supply Document. BPA continues to take comments on its conservation supply estimates and will continue research in the area. Reviews of data and assumptions to date indicate that these estimates are still reasonable. As research progresses and new information is developed, it will be incorporated into future Puget Sound studies.

Technical Potential. In general, the method begins with projections of numbers of units (for example, numbers of electrically heated single-family dwellings) from the load forecast, and costs and savings per unit from an inventory of available conservation and load management measures. The combination of this information yields an estimate of technical potential savings, savings that could be achieved if market constraints did not exist. Market constraints include such factors as unwillingness of some consumers to accept measures regardless of program incentives or delivery mechanism.

Market-Achievable Savings \& Penetration Rates. Given that market constraints do exist, and that some installed measures do not achieve all the intended savings, the technical potential estimates are reduced to arrive at estimates of market-achievable savings. The market-achievable savings represent maximum saturation of the market for each option. Penetration rates were developed to estimate how much of the market achievable savings could be accomplished by the years 1995, 2000, 2005, and 2010.

Base case. It is important to account for the current conservation plans of each of the four major Puget Sound utilities and the remaining utilities in the area so as not to overstate total Puget Sound area conservation potential. The potential savings that were estimated as available to address the transmission problem reflect the conservation savings that can be accomplished by either accelerating existing utility plans, or instituting plans above and beyond what is currently planned. The existing utility plans define the base case and largely reflect the directions BPA laid out in the 1990 Resource Program. Base case savings estimates are provided in Table IV-A-3.

Peak Estimates. Estimates of daily load shapes for normal and extreme peak days were developed for several of the options, taking advantage of BPA's extensive hourly end-use data. These data are collected as part of the End-Use Load \& Consumer Assessment Project (ELCAP) and provide actual metered data on the most important end-uses in the residential and commercial sectors. In general, the peak estimates were developed from estimates of annual energy savings, and daily load shapes are estimated based on ELCAP data.

Conservation \& Load Management Potential. Table IV-A-3 1ists the preliminary peak savings for the conservation and load management options 1 isted in Table IV-A-1. There are several notes of caution when reading Table IV-A-3. 
CONSERVATION \& LOAD MANAGEMENT POTENTIAL

IN THE PUGET SOUND AREA

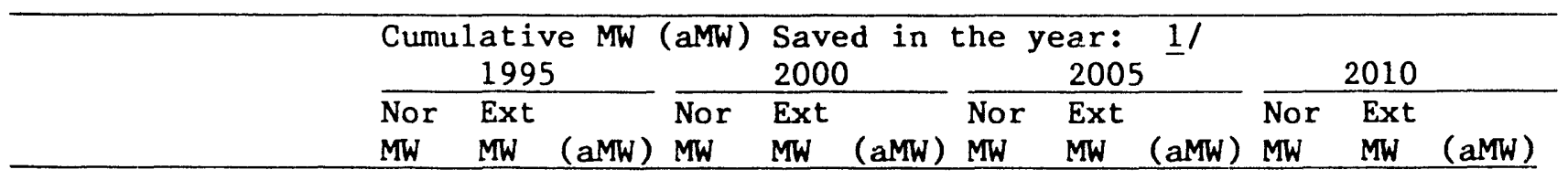

Base Line (Planned Conservation Savings) $\underline{2} /$

$\begin{array}{lrrrrrrrrrrrr}\text { Res Weatherization } & 99 & 130 & (23) & 165 & 217 & (37) & 206 & 271 & (47) & 228 & 300 & (52) \\ \text { Exstng Commercial } & 40 & 44 & (25) & 74 & 84 & (46) & 106 & 119 & (66) & 130 & 1.46 & (81) \\ \text { New Commercial } & 30 & 34 & (19) & 78 & 88 & (49) & 128 & 144 & (80) & 167 & 188 & (104) \\ \text { Industrial } & 20 & 21 & (20) & 51 & 52 & (50) & 80 & 82 & (79) & 93 & 95 & (91)\end{array}$

Conservation Savings Potential Above Base Line $\underline{3} /$

$\begin{array}{lrrrrrrrrrrrr}\text { Res Weatherization } & 19 & 25 & (4) & 71 & 95 & (16) & 31 & 41 & (7) & 9 & 12 & (2) \\ \text { Res Lo Flow Shower } & & & & & & & & & & & & \\ \quad \text { Heads 4/ } & 6 & 6 & (5) & 12 & 12 & (11) & 12 & 12 & (11) & 12 & 12 & (11) \\ \text { Exstng Commercial } & 0 & 0 & (0) & 38 & 43 & (24) & 62 & 70 & (39) & 94 & 106 & (59) \\ \text { New Commercial SI/ } & 0 & 0 & (0) & 0 & 0 & (0) & 0 & 0 & (0) & 0 & 0 & (0) \\ \text { Industrial } & 36 & 37 & (35) & 43 & 44 & (42) & 14 & 14 & (13) & 1 & 1 & (1)\end{array}$

Load Management $6 /$

$\begin{array}{llllllllllll}\text { Res Water Htr Pckg } 153 & 111 & \text { ( (6) } 372 & 269 & \text { (16) } 533 & 385 & \text { (23) } 534 & 385 & \text { (21) }\end{array}$

$\begin{array}{llllllllllll}\text { Res TOU Rates } & 93 & 101 & \text { ( 0) } 126 & 137 & \text { ( 0) } 128 & 140 & \text { ( } 0) & 131 & 143 & \text { ( } 0)\end{array}$

1/ Nor MW = normal year MW savings; Ext MW = extreme year MW savings; $\underline{\text { aMW }}=$ average MW (energy) savings per year. Cumulative savings in each reported year reflect the savings in that year occurring from units installed in prior years.

2/ Base line savings projections based on current utility plans and BPA's Resource Program; assumed to be accounted for in the forecast.

3/ Calculated by subtracting base 1 ine projected savings from accelerated program savings. BPA Supply Curves and utility projections used to calculate accelerated program savings.

4/ Market for low flow shower heads includes only existing homes; assumes few existing homes have low flow shower heads. Base line assumed to be zero.

5/ Aggressive planned new commercial conservation savings already captures $100 \%$ of market potential; therefore, no potential exists beyond base line.

6/ Load management data come from EPRI, Snohomish PUD pilot programs, vendors, etc. Some load management results still being developed. 
First, the estimates provided are the result of preliminary scoping efforts by the conservation and load management team. Although team members have significant experience with conservation, there is little familiarity with load management in the Northwest. Second, conservation options may interact with load management options, and as a result, they are not additive.

Load management cptions have the most potential for peak reduction. For example, residential time-of-use rates, if structured properly, could provide up to $143 \mathrm{MW}$ of extreme peak day savings by the year 2010, at low cost. In addition, conservation options are largely already planned; the increment of peak savings due to conservation above current plans therefore tends to be smal1.

Load Management. Load management options generally operate by causing loads to shift from peak hours to off-peak hours during the day. The challenge is to avoid creating another peak by shifting too much load. The teim developed a rule of thumb which constrained the maximum amount of "shiftable" load to $500 \mathrm{MW}$ shifted from the morning peak to the mid-morning valley. The $500 \mathrm{MW}$ accounts for the peak to valley difference on the Puget Sound area system load shape and also for electricity use by appliances when they are turned back on. Table IV-A-3 presents savings for two load management control options. However, it is recognized that other options such as space heat controls, thermal energy storage, etc., can be pursued to shift peak loads. Because of the 500 MW maximum shiftable load constraint and other issues related to these options, it was determined that water heat load management would be emphasized. Other options will be addressed further in Phase II of the study.

Costs. The costs of each option displayed in Table IV-A-4 and Table IV-A-5 include capital, incentive, administrative, and annual costs. These costs have been levelized to account for different measure lives and to make the savings estimates more consistent with the costs. For example, the costs in the year 2005 reflect the costs of the measures installed through 2005. This is consistent with the savings estimates for 2005 in Table IV-A- 3 which result from installation of measures through 2005 .

The costs for load management options are expressed in dollars "per peak $\mathrm{kW}$ saved. These costs have been developed from a combination of regional experiences and research documents, primarily from EPRI. The costs in Tables IV-A-4 vary by year and by peak day type even though the levelized costs are constant. The costs change because the peak savings themselves change by peak day type and between years.

The costs for the conservation options are exprossed in mills pror kWh. These costs were developed from a combination of recent utilily experituces and from data obtained from BPA's Resource Program document. The cost.s if the conservation options are all below the regional cost effectiveness ceiling of $50 \mathrm{mills} / \mathrm{kWh}$. They provide a cost effective energy resource apart from any peak benefits they can provide. In Phase II more emphasis will be placed on how to develop the conservation costs associated with peak savings. 


\section{IEVELIZED COSTS FOR LOAD MANAGEMENT PROGRAMS II \\ BY DAY TYPE \$/PEAK KILOWATT}

\begin{tabular}{lcccc}
\hline PRorRAM & 1995 & 2000 & 2005 & 2010 \\
\hline $\begin{array}{l}\text { Hot Water Controls 2/ } \\
\text { Normal Day Type }\end{array}$ & $\$ 57.20$ & $\$ 57.10$ & $\$ 57.10$ & $\$ 57.30$ \\
$\begin{array}{l}\text { Hot Water Controls } \\
\text { Extreme Day Type }\end{array}$ & $\$ 78.80$ & $\$ 79.00$ & $\$ 79.10$ & $\$ 79.50$ \\
$\begin{array}{l}\text { Residential Time of Use Rates } 3 /- \\
\text { Normal Day Type }\end{array}$ & $\$ 56.40$ & $\$ 56.40$ & $\$ 59.00$ & $\$ 63.40$ \\
$\begin{array}{l}\text { Residential Time of Use Rates - } \\
\text { Extreme Day Type }\end{array}$ & $\$ 52.00$ & $\$ 52.00$ & $\$ 54.20$ & $\$ 58.10$ \\
\end{tabular}

1/ Levelized at 3 percent over equipment life. Levelized costs are annual costs comparable to annual peak savings.

2/ Equipment costs are $\$ 358$ per hot water heater. Annual costs are $\$ 28$ per tank for incentives and administrative costs.

3/ Equipment costs are $\$ 115$. Annual costs are $\$ 22$ per year for incentives and administrative costs. 
TABLE IV-A-5

\section{LEVELIZED COST OF CONSERVATION PROGRAMS 1 - \\ MILLS/KWH}

$\begin{array}{ll}\text { Residential Weatherization } & 40 \\ \text { Low-flow Shower Heads } & 19 \\ \text { Existing Commercial } & 21 \\ \text { New Commercial } & 14 \\ \text { Industrial } & 15\end{array}$

1/ Costs are levelized at 3 percent over equipment 1 ife and divided by expected average annual energy savings. Cost data are from the Draft 1990 Conservation Resources Supply Document published by BPA. Program evaluation reports were also used. 
Fuel Switching. The switching of electricity loads to other fuels, termed "fuel switching," is another option that has attracted attention. While fuel switching might appear to have a large potential for peak reduction, some of this results from market forces and thus is already reflected in the load forecast described in Chapter II.

Fuel switching presents a number of concerns, including regulatory policy issues, fuel availability, reliability, distribution and price issues, and environmental impacts. The significance of these concerns will be addressed in Phase II.

Preliminary estimates indicate that there are approximately 600 MW of peak savings potential available from fuel switching residential space and water heat. This estimate is based on moderate assumptions about gas availability, the emphasized market niche, and market saturation.

As this subject receives more regional attention and the many uncertainties are discussed further, some fuel switching issues may be resolved in other forums. The topic of fuel switching will continue to be addressed in the context of the Puget Sound study. The extent to which it is considered as a solution is dependent on the resolution of a number of issues and on the further development of estimates of gas availability, fuel switching costs, and MW potential.

Remaining Conservation and Load Management Issues. Several factors 1 imit the accuracy of the conservation and load management estimates. These include:

1) Lack of data on the capacity impacts of various conservation and load management programs;

2) Lack of experience in load management and rates programs, which make it difficult to judge customer response (Estimates of penetration and saturation rates are conservative.);

3) Dimensions of the transmission problem not yet fully understood (Does a problem occur frequently, every year, or infrequently, once every 20 years?);

4) Lack of resolution of several issies that could significantly change the impact of conservation and load management options on peak reduction (Most important of these is the issue of how programs will be funded. Another is the accounting for costs of conservation programs pursued to meet energy requirements.);

5) Policy issues surrounding fuel switching which make it difficult to quantify as an option for peak reduction.

In Phase II it may be necessary to reconsider the assumptions underlying these estimates, both in examining new technologies and in estimating penetration and market saturation rates. This could result in less conservative estimates of conservation and load management potential.

There may also be opportunities to combine options to create programs that will result in greater savings. For example, pairing time-of-use rates with residential thermal heat storage may provide better results than either option alone. Such strategies may also allow expansion into other approaches which alone may not show much potential for reducing peak or being accepted by customers. Combinations of options will be addressed in Phase II. 


\section{B. LOCAL GENERATION}

Background. Sufficient generating resources exist within the Pacific Northwest region to meet both peak and energy requirements in the Puget sound area. However, the bulk of these resources are located east of the Cascade Mountains and require long distance transmission to serve loads in the Puget Sound area. As explained in Chapter I, the existing transmission system delivering power to the area is increasingly strained as peak loads continue to grow.

"Local" generation is defined for the purpose of this study as any power source located within the Puget Sound area, extending north to the Canadian border, east to the Cascade Mountains, south to Chehalis, and west to the Pacific 0cean. New local generation offers several distinct advantages that relate directly to the peak delivery problem: peaking capacity and reactive voltage support. In addition, generation alternatives have value associated with their energy component.

Information Sources. Major sources used to develop the information in this section were: the material being prepared for the Northwest Power planning Council's 1990 Power Plan; BPA's Draft 1990 Generating Resource Supply Document; BPA's "Assessment of Commercial and Industrial Cogeneration Potential in the Pacific Northwest"; the Northwest Hydro Database; and an assessment of standby generation performed by a contractor. These sources of information along with the data developed by the technical review group provided the information from which the local generation supply was developed.

Projections of future resource acquisitions from the utility members of the study team were used to corroborate BPA and Northwest Power Planning Council estimates. The Puget Sound area utilities, as well as others in the region, are actively seeking resource development options. At this point, most plans are in the preliminary stages, so continuing changes in resource prospects should be expected.

Methodology. BPA and the Northwest Power Planning Council have collaborated in assessing potential generating resources for the region. These assessments, which have been refined through numerous public involvement processes, formed the foundation of the analysis of local generation for the Puget Sound area.

The estimates for Puget Sound area cogeneration were developed by breaking out sub-regions in BPA's cogeneration study. The methodology for developing the cogeneration potential within the subregion is identical with that used in the cogeneration study.

The potential for small hydro was developed in a similar mamur. A subregion consisting of the Puget Sound area was developed and then the hydro potential for that region was projected using the Northwest Hydro Database. 
Standby generation is a rough estimate of the amount of resource that might be available in the Puget Sound area based on the experiences of utilities in other parts of the country. Several technical and institutional issues would have to be investigated more thoroughly to assess the proper role of this resource.

Combustion turbines are a known technology with predictable capital costs. The capacity that can be installed does not have an inherent limit, but rather is constrained by siting and fuel delivery factors. Further study is required to assess the application of combustion turbines in the puget Sound area.

WNP-3 costs and performance figures are taken from BPA's 1990 Resource Program documentation. Although WNP-3 is located at the southern end of the Puget Sound area under study, it has potential benefit for both capacity and reactive support. Further study will be required to determine its likely contribution.

A coal resource using advanced technologies (i.e. atmospheric fluidized bed or gasification) has been included for further analysis. These technologies can be developed in relatively small increments and have reduced emissions compared to conventional coal conversion technologies. They can also be developed in cogeneration applications.

Local Generation Supply. The results of Phase I generating resource analyses are displayed in Tables IV-B-1 through $I V-B-5$ on the following pages. The "universe" of generic generation alternatives identified during Phase $I$ is shown in Table IV-B-1. This 1 ist of resources was then subjected to the screening criteria described in Table IV-B-3. The technologies that passed the initial screening are 1 isted in Table IV-B-2. These technologies will be analyzed further and evaluated as components of alternative strategies in Phase II. Table IV-B-3 summarizes the results of the screening and identifies those resource technologies that were eliminated.

Table IV-B-4 displays operating characteristics of the resource types recommended for further consideration. The data were developed from the references cited earlier. These data are not based on site-specific studies in the Puget Sound area, but are thought to be representative of potential Puget Sound area resource development.

Table IV-B-5 shows energy characteristics, levelized costs (in 1988 \$) and construction lead times for each of the resource types recommended for further study. These data were developed from the same sources.

No detailed information on the technologies that did not pass screening is presented here. However, all source materials and documentation are available for review upon request. It should also be pointed out that local generation options that were not found suitable for solving the Puget Scund peak load problem may still warrant further consideration in utility energy resource programs. 


\section{UNIVERSE OF GENERATION ALTERNATIVES}

0il and Gas Combustion

- Steam

- Combustion Turbines

- Combined Cycle

Coal

- Conventional Coal

- Advanced Coal (FBC, Gasification)

Nuclear Fission - Completion of WNP-3

Nuclear Fusion

Geothermal

Hydroelectric

- Conventional

- Pumped Storage

- Water Supply (Pressure Reduction)

Biomass Fired - Direct Combustion or Gasification

Municipal Solid Waste - Mass Burn, RDF or Gasification

Cogeneration

Wind

Solar Thermal Electric

Photovoltaics

Ocean - Wave and/or Tidal

Hydrogen

Fuel Cells

Storage Systems - Compressed Air

- Utility Batteries

- Superconducting Magnetic Energy

Standby Generation 
Table IV-B-2

\section{GENERATION TECHNOLOGIES RECOMMENDED FOR FURTHER STUDY}

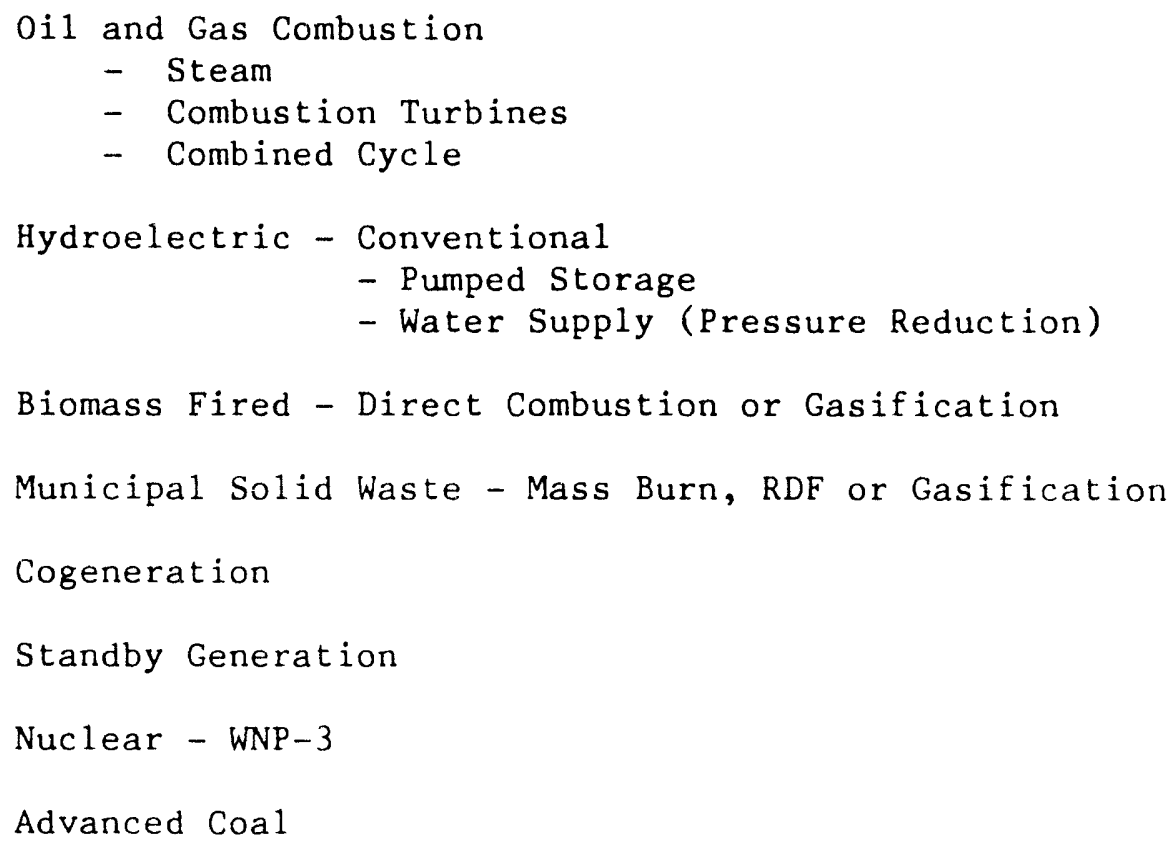


Table IV-B-3

\section{GENERATION TECHNOLOGIES EXCIUDED EROM FURTHER CONSIDERATION}

\begin{abstract}
Generation Technologies Excluded from Further Consideration
\end{abstract}

Exclusion Based on

Not Meeting the

Screening Criteria(*)

$\begin{array}{ll}\text { Conventional Coal (**) } & 5 \\ \text { Advanced Nuclear } & 1,2,4 \& 5 \\ \text { Geothermal } & 2 \\ \text { Wind } & 2,3 \\ \text { Solar Thermal Electric } & 1,2 \& 4 \\ \text { Photovoltaics } & 2,3 \& 4 \\ \text { Ocean - Wave and/or Tidal } & 1,2,3 \& 4 \\ \text { Hydrogen } & 1,2, \& 4 \\ \begin{array}{l}\text { Fuel Cel1s } \\ \text { Storage Systems } \\ \quad \text { - Compressed Air } \\ \quad \text { - Utility Batteries } \\ \quad \text { - Superconducting Magnetic Energy }\end{array} & 1,2 \& 4 \\ \end{array}$

(*) 1. Technology maturity

2. Commercially available technology/Confirmed resource

3. Available during winter and any other critical outage condition

4. Competitive cost ( $50 \mathrm{mills} / \mathrm{kWh}$ or less) levelized real (1988 \$)

5. On line by 2002 .

(**) Conventional coal may be feasible but cannot meet the 2002 on-1ine date. Advanced coal technologies are included for further consideration. 
Table IV-B-4

\section{PEAK POTENTIAL AND OPERATING CHARACTERISTICS}

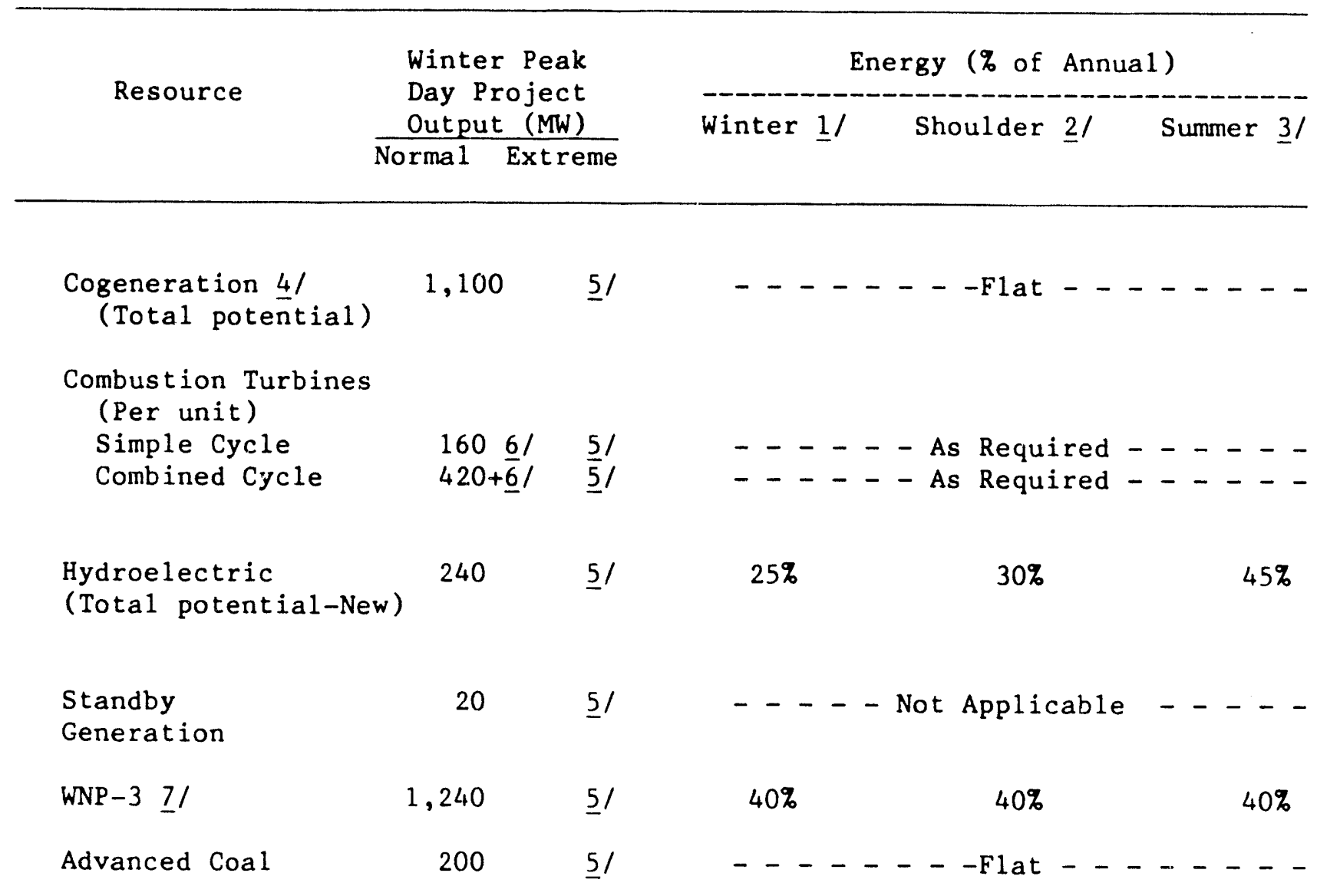

1/ Winter includes November, December, January and February

$\underline{2} /$ Summer includes May, June, July and August

3/ Shoulder includes September, October, March and April

$4 /$ Includes municipal solid waste and biomass-fired opportunities

ㄱ/ Winter peak day project output is assumed to equal installed capacity. (More study is required.)

6/ These are typical sizes for single and combined cycle installation. The actual amount installed depends on specific factors such as siting constraints and fuel arrangements.

If Although WNP-3 is located at the southern end of the Puget Sound area under study, it has potential benefit for both capacity and reactive support. Further study will be required to determine its likely contribution. 
Table IV-B-5

\section{ENERGY, LEVELIZED COST, AND LEAD TIMES}

\begin{tabular}{|c|c|c|c|c|}
\hline Resource & $\begin{array}{l}\text { Installed } \\
\text { Capacity } \\
\text { (MW) }\end{array}$ & $\begin{array}{l}\text { Energy } \\
(\mathrm{aMW})\end{array}$ & $\begin{array}{c}\text { Levelized } \\
\text { Cost } \\
(\mathrm{mi} 11 \mathrm{~s} / \mathrm{kWh}, \\
1988 \$) \\
\end{array}$ & $\begin{array}{l}\text { Lead Time } \\
\text { (Years) }\end{array}$ \\
\hline Cogeneration $1 /$ & 1,100 & 950 & $35-55$ & $2-4$ \\
\hline $\begin{array}{l}\text { Combustion Turbin } \\
\text { Simple Cycle } \\
\text { Combined Cycle }\end{array}$ & $\begin{array}{l}160 \\
420+\frac{3}{3} /\end{array}$ & $\begin{array}{l}-- \\
--\end{array}$ & $\frac{21}{2}$ & $\begin{array}{l}3-4 \\
4-5\end{array}$ \\
\hline $\begin{array}{l}\text { Hydroelectric } \\
\text { (New) }\end{array}$ & 240 & 100 & $16-55$ & $3-6$ \\
\hline $\begin{array}{l}\text { Standby } \\
\text { Generation }\end{array}$ & 20 & -- & $52-61$ & $<1$ \\
\hline WNP-3 & 1,240 & 806 & 34 & 8 \\
\hline Advanced Coal & $2003 /$ & 170 & $40-50$ & 7 \\
\hline
\end{tabular}

1/ Includes municipal solid waste and biomass-fired opportunities

2/ Combustion turbine (CT) cost depends on how they are used. When displaced by nonfirm hydro power, combined cycle CT's have a cost of 26-34 mills/kWh. If installed for capacity only, simple cycle CT's have a capital cost of $400-500 \$ / \mathrm{KW}$. CT's are considered to be a viable option for the Puget Sound area. Actual application and the verification of cost will require further study.

3/ These are typical unit sizes. The actual number of units installed depends on specific factors such as siting constraints and fuel arrangements. 


\section{TRANSMISSION}

Background. Thirty-nine transmission options were studied during Phase I using constant power load models. Six options, listed in Table IV-C-1, are considered technically and economically feasible. Since the five transmission line options are similar, only one is described here. A transmission line option and a reactive option will be carried forward in the planning EIS process.

Options such as $765-\mathrm{kV}$ double circuit and $\pm 500-\mathrm{kV}$ direct current (DC) are technically feasible, but are too costly. In addition, 28 other $500-\mathrm{kV}$ alternating current ( $A C$ ) options, listed in Table IV-C-2, were found to be infeasible or Lechnically inferior.

Upgrade of existing single circuit $345-\mathrm{kV}$ lines to $500-\mathrm{kV}$ is not practical since audible noise and EMF considerations require a minimum of 3 -conductor bundles. The existing towers are not capable of supporting the increased weight. It may be feasible to convert a double circuit $345-\mathrm{kV}$ line to single circuit $500-\mathrm{kV}$, but the capacity increase would be 1 imited.

A complete rebuild of an existing circuit is possible. This would allow the replacement of a lower capacity line (or lines) with a higher capacity circuit(s) using existing right-of-way or minimizing the need for new right-of-way. However, the capacity of the replaced circuit is lost and it may be difficult to operate the system reliably during construction when the old line is taken out of service. Also, rebuildable lines may not be located where transmission reinforcement is needed or would best be placed. Rebuild options will be explored in greater detail in Phase II.

Determinations of feasibility were based on assumptions and information available at the time. Any of the options not being carried forward into Phase II could be re-evaluated if further engineering or environmental studies provide information that could affect their feasibility.

\section{Viable Transmission Alternatives}

\section{Cross-Cascade 500-kV AC Double-Circuit Line}

Puget Sound Area Voltage Stability Performance. With a new 1 ine added, the three critical outages for the Puget Sound area are 1) loss of one Coulee-Rave: $500-\mathrm{kV}$ 1 ine during abnormally cold weather, 2) loss of the Trojan nuclear plant with one Centralia unit previously out of service, also during abnormally cold weather, and 3) simultaneous loss of both Coulee-Raver 500-kV lines during normal winter peak loads.

A new Cross-Cascade 500-kV AC double circuit line alone will not fully solve the Puget Sound voltage/stability problem and provide the required reactive margins for the critical outages. The 500/230-kV transformer project in North Seattle will also help reduce the reactive deficit, but will still not provide the necessary reactive margin. A 300 MVAR Static: VAR Compensator (SVC) is also needed in the Puget Sound area at the Mapl" Valley Substation to provide this margin. 
This SVC will need to be increased to 500 MVARs in later years to keep up with the expected load growth. Also, additional 500-kV shunt capacitors will be needed at Monroe and Snoqualmie Substations between 2000 and 2004 .

Puget Sound Area Thermal Overload Requirements. If the Cross-Cascade line is added, numerous problems are aggravated in the North Seattle area during winter conditions. These would require local reinforcement.

Portland Area Voltage Stability Performance. The critical outage for the Portland area is loss of the Trojan nuclear plant with one Centralia generating unit previously out of service during abnormally cold weather loads. The addition of the new 1 ine into the Puget Sound area will not provide the necessary margins in the Portland area by itself. A 300 MVAR SVC is needed at Keeler substation. This SVC will need to be increased to 500 MVARs in later years to keep up with the load growth. Also, additional $500-\mathrm{kV}$ shunt capacitors will be needed at Ostrander and Pearl Substations between the years 2000 and 2004 .

Coulee/Chief Joseph Area Performance/Effects. Loading increases on the $500 / 230-\mathrm{kV}$ transformers with a new cross mountain line. A second Chief Joe $500 / 230-k V$ transformer is needed to prevent overloads following outages of the existing Chief Joe 500/230-kV transformer, Coulee $500 / 230-k V$ transformer, or Coulee-Chief Joe 500-kV line during spring with 1800 MW Custer to Ingledow power flow.

Transmission Line Option Summary.

1994 Add 300 MVAR SVC on Maple Valley 230-kV bus, Add 300 MVAR SVC on Keeler $230-\mathrm{kV}$ bus, Add Snoqualmie Switching Station, and Eight 1 ine upgrades.

1996 Add Chief Joseph-Snoqualmie/Monroe 500-kV double circuit 1 ine; Add Snoking 500/230-kV transformer tapping Monroe-Snoqualmie 500-kV Line and using existing 500-kV constructed 1 ine into Snoking; Add Snoking-Bothell 230-kV line 非; add Snoqualmie 500-kV shunt reactor; and Eight 1 ine upgrades.

2000 Upgrade Maple Valley SVC to 500 MVAR; and Upgrade Keeler SVC to 500 MVAR;

Add $500-\mathrm{kV}$ shunt capacitor bank at Monroe;

Add $500-\mathrm{kV}$ shunt capacitor bank at Pearl; and Add $500-\mathrm{kV}$ shunt capacitor bank at Ostrander.

2004 Add 500-kV shunt capacitor bank at Snoqualmie Add $500-\mathrm{kV}$ shunt capacitor bank at ostrander

2005 Add Monroe-Snohomish 500-kV 1ine, operate at 230-kV initiall1y.

2010 Add Snohomish 500/230-kV 1800 MVA transformer; Loop Bothel1-Diablo 230-kV line into Snohomish; and Convert Monroe-Snohomish 1 ine to $500-k V$ operation. 


\section{Reactive Option}

Puget Sound Area Voltage Stability Performance. Assumed voltage stability criteria can be achieved in 1996 with the addition of four 300 MVAR SVC's (Snohomish, Maple Valley, Covington, and Keeler) and two series capacitor stations ( 1 on each Coulee-Raver $500-\mathrm{kV}$ 1ine about 50 miles from Raver, 20 percent $2600 \mathrm{~A}$ ).

In 2000, load growth and system design for the simultaneous loss of both Coulee-Raver $500-\mathrm{kV}$ lines requires three additional series capacitor stations on the other three existing cross Cascades 500-kV lines (25 percent $3200 \mathrm{~A}$ midline on Chief Joe-Monroe 500,35 percent $2300 \mathrm{~A}$ on each Naneum-Raver 500 line). Another 324 MVAR $500-\mathrm{kV}$ shunt capacitor bank is needed at Monroe.

By 2004, load growth causes the need for all the series capacitors to be in service with no outage during abnormal cold weather. Three more series capacitor stations need to be added for planning contingencies (25 percent more compensation on Chief Joe-Monroe and 35 percent more compensation on each Naneum-Raver line). Two 500-kV 324 MVAR shunt capacitor banks are needed at Snoqualmie.

Portland Area Voltage Stability Performance. A 300 MVAR SVC is needed at Keeler in 1996 and an additional 300 MVAR SVC is needed at Ostrander in 2004 to satisfy voltage stability criteria for a Trojan outage during abnormal cold with one Centralia unit down.

\section{Reactive Option Summary}

1994300 MVAR SVC on Maple Valley $230-\mathrm{kV}$ bus, 300 MVAR SVC on Keeler $230-\mathrm{kV}$ bus, Add Snoqualmie Switching Station, and Eight Line Upgrades.

1996300 MVAR SVC at Snohomish

300 MVAR SVC at Covington

20 percent more series comp on Coulee-Raver 非 1 and $\equiv^{2}$ between Columbia and Raver

200025 percent series comp on Chief Joe-Monroe midline

35 percent series comp on Naneum-Raver 非 1 \& 非 2 between Naneum and Raver

3 rd parallel circuit from Monroe Tap to Sedro Tap

Add 500-kV shunt capacitor banks at Monroe, Pearl, and 0strander

2004 Add 2-500-kV shunt capacitor banks at Snoqualmie

Add $500-\mathrm{kV}$ shunt capacitor bank at Ostrander

25 percent more series comp on Chief Joe-Monroe

35 percent more series comp on Naneum-Raver 非 1 and $\left.\right|_{2} 2$

2nd Maple Valley 500/230-kV transformer

2nd Raver-Snoqualmie 500-kV line

300 MVAR SVC at Ostrander 


\section{PUGET SOUND REINFORCEMENT STUDY -- PLANNING FOR PEAK POWER NEEDS}

Costs and Transmission Efficiency Benefits of Viable Alternatives.

\begin{tabular}{|c|c|c|c|c|}
\hline \multicolumn{5}{|c|}{$\begin{array}{l}\text { COST COMPARISON } \\
(\text { A11 Costs in Millions, } 1990 \$)\end{array}$} \\
\hline & $1990-1995$ & $1996-2000$ & $2001-2005$ & $2006-2010$ \\
\hline Transmission Line Option & 60 & 242 & 18 & 14 \\
\hline \multirow[t]{3}{*}{ Reactive Option } & 60 & 105 & 76 & 0 \\
\hline & \multicolumn{3}{|c|}{$\begin{array}{c}\text { LOSS SAVINGS COMPARISON } \\
(\text { Peak MW })\end{array}$} & \\
\hline & 1996 & 2000 & $2004(1)$ & $2004+(1)$ \\
\hline Transmission Line Option & 73.9 & 86.1 & 77.1 & 84.9 \\
\hline Reactive Option & 2.4 & 10.1 & $-0-$ & $-0-$ \\
\hline
\end{tabular}

1/ The loss savings for 1996 and 2000 are referenced against the base transmission system for each year. The loss savings for 2004 are referenced against the Reactive Plan. 
Tab1e IV-C-1

\section{TRANSMISSION OPTIONS CONSIDERED TECHNICALLY \& ECONOMICALLY FEASIBLE}

1. Chief Joe-Monroe 500-kV double circuit 1 ine.

2. Chief Joe-Snoqualmie 500-kV double circuit 1 ine.

3. Chief Joe-Snoqualmie/Monroe $500-\mathrm{kV}$ double circuit 1 ine.

4. Hanford-Snoqualmie 500-kV double circuit line.

5. Sickler-Snoqualmie 500-kV double circuit line and Naneum Switchyard.

6. Reactive Alternative 
Table IV-C-2

\section{TRANSMISSION OPTIONS NOT CARRIBD FORWARD INTO PHASE II}

1. Chief Joe-Raver $500-\mathrm{kV}$ double circuit 1 ine.

2. Chief Joe-Raver 500-kV double circuit \& Raver-Snoqualmie 500-kV 非 1 ines.

3. Coulee-Raver 500-kV double circuit line.

4. Ashe-Snoqualmie 500-kV double circuit line.

5. Chief Joe-Monroe/Snoqualmie 500-kV double circuit, add

kaver-Snoqualmie $\left.\right|^{2} 2$ and use with one existing Coulee-Raver 1 ine to form Coulee-Snoqualmie 500-kV line.

6. Chief Joe-Coulee 500-kV single circuit line.

7. Monroe-Raver-Paul 500-kV single circuit 1 ine.

8. Monroe-Raver-0lympia 500-kV single circuit line.

9. Naneum Switchyard (tie Coulee-Raver lines, Vantage-Raver, and Sickler-Raver lines together near Ellensburg)

10. Naneum Switchyard and Grand Coulee-Naneum 500-kV double circuit line.

11. Naneum Switchyard with shunt capacitors.

12. Naneum Switchyard with series capacitors within station.

13. Naneurn Switchyard, Naneum-Snoqualmie 500-kV double-circuit line.

14. Naneum Switchyard, Naneum-Monroe 500-kV double-circuit 1 ine.

15. Naneum Switchyard, 500-kV single circuit tap line to Hanford-Grand Coulee.

16. Naneum Switchyard, Naneum-Hanford 500-kV single circuit line.

17. 500-kV single circuit tap line from Sickler to existing Grand Coulee-Hanford 500-kV 1ine.

18. Sickler-Monroe 500-kV double circuit line.

19. Sickler-Monroe 500-kV double circuit line, 500-kV single circuit tap line from Sickler to existing Grand Coulee-Hanford 500-kV line.

20. Sickler-Snoqualmie 500-kV double circuit line.

21. John Day-Paul 500-kV double circuit line.

22. John Day-Al1ston 500-kV double circuit 1 ine.

23. John Day-Allston 500-kV double circuit line, Monroe-Raver-01ympia 500-kV single circuit line.

24. Lower Monumental-Hanford 70 percent Series Compensation - 136 MVAR.

25. Raver-Snoqualmie 500-kV single circuit 1 ine, Snoqualmie switchyard.

26. Raver-Snoqualmie 500-kV single circuit line, Raver-Covington $500-\mathrm{kV}$ single circuit line.

27. Raver-Snoqualmie, Raver-Covington, and Raver-Tacoma 500-kV single circuit lines.

28. Covington-Maple Valley $500-\mathrm{kV}$ single circuit 1 ine, Covington and Maple Valley switchyards. 


\section{LOAD CURTAILMENT}

Background. Load curtailment is a reduction in the amount of electricity consumed by an end user. Load curtailment for purposes of this study needs to be differentiated from conservation and load management. There are generally three methods that can be used to reduce the amount of electrical demand and energy consumed by an end user. The first method is to reduce the amount of electricity used through energy conservation measures, potentially reducing both peak and energy loads. The second method is to shift the pattern of energy use from a specific point in time to another, reducing demand while holding total energy consumption relatively constant. The third method is to limit the amount of electricity and simply forego its use. The first two methods, for this analysis, are being defined as conservation and load management alternatives. The third is load curtailment.

For purposes of this study, load curtailment is defined as a reduction of demand during times of system stress that is limited to a short, nonrecurring period during which a utility has identified a need to reduce demand temporarily. However, curtailment was studied for use on a planning basis rather than as a short term method for dealing with a temporary operating problem. Long term load reductions accomplished through capital investment incentives or focused toward a reduction of energy consumption would not be considered curtailment.

Various methods of curtailing demand were identified and studied to determine whether they would be of value in effecting a net reduction in demand in the Puget Sound area. As new options were suggested, the load curtailment study team coordinated with the load management study team to assure that overlap and omission were avoided. Options suggested included voluntary curtailment, rotating "rolling" blackouts (involuntary curtailment), voluntary industrial curtailment without affecting production, multi-utility curtailment, curtailment cooperatives (co-op), industrial contractual curtailment, and curtailment rates. BPA's existing DSI contracts were also studied to determine what potential might exist.

After more thorough analysis, the study team narrowed the curtailment options to three different types--voluntary, involuntary, and contractual. Voluntary curtailment includes curtailment which could be achieved in the residential, commercial, and industrial sectors at the request of utilities and government agencies. Involuntary curtailment would be implemented through rolling blackouts by utilities without any action by end-use consumers. Contractual curtailment includes both industrial curtailment contracts and curtailment co-ops. Multi-utility curtailment was thought to be a special case of contractual or voluntary curtailment. Curtailment rates were not studied as a separate type of curtailment because the rate would be an implementation mechanism under both industrial and co-op curtailment contracts. Each of these types is discussed in detail later in this section.

Methodology. To estimate the amount of potential for curtailment in the Puge Sound Area, information $f$ :om utilities outside the region was reviewed, and a survey was distributed to various industrial customers of the four large utilities in the Puget Sound area. The industrial sector was chosen because 
large blocks of load might be available, and the smaller number of consumers made it easier to obtain survey results. These customers were asked to identify their typical peak January load and the amount of load they might be willing to make available for curtailment at three different rates ranging from $\$ 3 / \mathrm{kW}-\mathrm{yr}$ to $\$ 25 / \mathrm{kW}-\mathrm{yr}$. The assumptions in the survey were that curtailment would be called for no more than once a winter season with 30 minutes advance notice and that the interruption would last for no more than four hours. Some survey recipients also identified loads that could be curtailed for up to twelve hours.

Curtailment programs from other utilities throughout the country with experience in load curtailment were reviewed to gain a better understanding of the local potential for curtailment and its associated issues. Some of the utilities whose programs were reviewed included Potomac Electric Power Company (PEPCO), Boston Edison Company (BECo), and Sacramento Municipal Utility District (SMUD). Although these utilities are located in other parts of the country and are subject to different load characteristics and conditions than those which exist in the Puget Sound area, the team felt that similar curtailment resources might be developed in the Puget Sound area.

Curtailment Potential. The results of the survey identified the following potential industrial load curtailment resources:

\begin{tabular}{c} 
Curtailment Rate \\
\hline$\$ 3 / \mathrm{kW}-\mathrm{yr}$ \\
$\$ 10 / \mathrm{kW}-\mathrm{yr}$ \\
$\$ 25 / \mathrm{kW}-\mathrm{yr}$
\end{tabular}

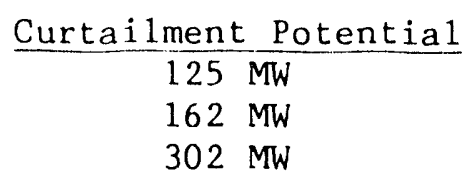

As a check against the compensation offered by other utilities in their curtailment programs a limited analysis was performed to determine what type of rate structure might be appropriate for a curtailment program. That analysis suggested that curtailment rates should be established somewhere between BPA's value of DSI reserves and the cost of the next least-cost alternative solution. The range of suggested rates was similar to the rates proposed in the industrial survey, lending credibility to the survey data.

After analyzing all the information gathered during the study, the study team concluded that there are four basic kinds of curtailment resources that could be used to help avoid a voltage collapse in the Puget Sound area. These include voluntary curtailment, contractual curtailment, curtailment co-ops, and involuntary curtailment or rolling blackouts. The consensus of the study team was that only the first three would be considered good candidates for an overall package to be used as a long term solution for the voltage collapse problem. A summary of curtailment potential of the four kinds of resources is shown in Table IV-D-1. Delivery mechanisms will be addressed during Phase II.

Rolling blackouts were considered to be an emergency or short term type of resource. If implemented, it is likely that additional control equipment would need to be installed by utilities to make rolling blackouts an effective curtailment resource. The duration of the blackout would need to be precisely controlled in order to avoid recovery peak problems. If the electrical system in the Puget Sound area were in imminent danger of a voltage collapse, rolling 
Table IV-D-1

\section{CURTAILMENT POIENTIAL IN THE PUGET SONDD AREA}

\begin{tabular}{llcl}
\hline Curtailment Resource & Sector & Cost to Utility & Amount \\
\hline Voluntary & $\begin{array}{l}\text { Residential } \\
\text { Commercial } \\
\text { Industrial }\end{array}$ & No Cost & $\begin{array}{l}0.1-10 \% \\
(10-860 \mathrm{MW})\end{array}$ \\
Contractual & Industrial & $\$ 3-100 / \mathrm{kW}-\mathrm{yr}$ & $100-900+\mathrm{MW}$ \\
Curtailment Co-ops & $\begin{array}{l}\text { Commercial } \\
\text { Industrial }\end{array}$ & $\$ 3-25 / \mathrm{kW}-\mathrm{yr}$ & $50-300 \mathrm{MW}$ \\
$\begin{array}{l}\text { Rolling Blackouts } \\
\text { (Involuntary) }\end{array}$ & $\begin{array}{l}\text { Commercial } \\
\text { Industrial }\end{array}$ & Control Cost & $\begin{array}{l}\text { Amoun } \\
\text { but needed } \\
\text { recovery peaks }\end{array}$ \\
& & & \\
\hline
\end{tabular}


blackouts could provide adequate load reduction to avoid a widespread outage, but the impacts it would create make it unsuitable as a long term solution. Industries would be thrown into chaos if they were subjected to half-hour to hour outages repeated every one or two hours. Such a scheme would effectively curtail the entire load of many industries for the duration of the system problem. Workers might also be subjected to unacceptable dangers associated with production processes. The general public would also face various hazards associated with the sudden interruption of electricity, and in general, safety problems arising from rolling blackouts would be great enough to cause this option to be eliminated as a longer term resource.

of the three remaining kinds of curtailment resources, the study team concluded that the following amounts of load curtailment might be achieved in the Puget Sound area, depending on how actively they were pursued:

Voluntary Curtailment. The study team estimated that between a 0.1 and 10 percent $(10-860 \mathrm{MW})$ reduction in demand could be achieved with a voluntary load curtailment program. Under such a program, businesses and the general public would be notified by radio and/or television of a need to reduce electricity use. This type of program could be implemented with a minimum of preparation and cost. The amount of reduction would depend on various conditions at the time.

Factors which would reduce the amount of load curtailed include the frequency with which curtailment is called upon, the duration of the load reduction, weather conditions, and market conditions. The team felt that, as load grew to the point where curtailment were needed more and more of ten, the amount of curtailment achievable on a voluntary basis would diminish. However, there may be some individuals or businesses that would always be willing to curtail use no matter how often it was asked; thus there would always some amount of curtailment available. Weather would also play a big factor in determining the amount of voluntary curtailment that could be achieved. Residential customers would be less likely to turn off electric heaters if the risk of freezing pipes was great due to extremely cold weather conditions. Market conditions would especially affect the amount of voluntary curtailment which might be achievable from the commercial and industrial sectors. If companies were in financial stress they would be less likely to curtail voluntarily.

This type of curtailment resource would generally be available to utilities without direct compensation cost, however it was recognized that individual customers may be subjected to other costs and impacts associated with their decision to curtail use. Utilities would need to devote staff resources to working out implementation details with local media and to educate the general public regarding how to respond to the utility's call for curtailment.

Members of the study team also determined that voluntary curtailment may not be as effective in combating a voltage collapse problem because of the length of time it would take to achieve the needed reduction. In a scenario where a key transmission line was suddenly taken out of service causing a voltage drop, a reaction would be needed in a matter of minutes to prevent system collapse. The time required for the media to ask for voluntary curtailment 
might be too long. By the time the public could react, the situation would have already been resolved by either stabilizing or collapsing.

This may be used more effectively as a preventative resource called upon either prior to an actual system problem or as a fill-in measure after immediate steps are taken to stabilize the system but before other resources can be put into place. A drawback of using voluntary curtailment in this manner is that utility customers may begin to doubt the need for curtailment over a longer period of time. If utilities call for voluntary curtailment as a preventative measure too frequently, without demonstrating to the public an actual need, customers might eventually curtail less or not at a11. The utilities could soon be viewed as "crying wolf."

Contractual Curtailment. Based on the results of the utility survey, it is estimated that between 100 and $900 \mathrm{MW}$ of curtailment could be achieved over a 2-year phase-in period by contracting with individual industrial customers in the Puget Sound area. This is in addition to existing curtailment contracts within the area. Under a curtailment contract, a utility would negotiate with interested industrial customers in its service area for specific amounts of curtailment based on various warning, frequency, and duration parameters. If there were a need for curtailment, the utility would implement the curtailment resource in one of a number of ways. In turn, the utility would compensate the industry in the form of a rate reduction.

Implementation methods include manual interruption by either the customer or utility, undervoltage load dropping, transfer trip load dropping, and a method of load dropping based on the Supervisory Control And Data Acquisition (SCADA) system. The method to be used would be established in each contract, allowing flexibility in addressing specific concerns and impacts for each customer. Contracts allowing for automated interruption would provide a more responsive resource. However, in the case of processes which could not tolerate automated interruptions or where such an interruption would create dangerous health or safety problems, the load could be interrupted manually by either the customer or serving utility.

The survey indicated a willingness on the part of some industrial customers to consider between $100 \mathrm{MW}$ and $300 \mathrm{MW}$ of contractual curtailment at incentive amounts of between $\$ 3 / \mathrm{kW}-\mathrm{yr}$ and $\$ 25 / \mathrm{kW}-\mathrm{yr}$. The total peak demand of the customers responding to the survey was approximately 451 MW out of a total 1990 estimated Puget Sound area peak industrial demand of 1,449 MW.

Extrapolating the data suggests that approximately $900 \mathrm{MW}$ of curtailment might be available if the industrial customers were compensated at a rate of $\$ 100 / \mathrm{kW}-\mathrm{yr}$. The $\$ 100 / \mathrm{kW}-\mathrm{yr}$ is at the upper end of compensation rates that have been used in other parts of the country. Combining the low and high estimates indicates that between $100 \mathrm{MW}$ and $900 \mathrm{MW}$ of industrial contractual curtailment might be available in the Puget Sound Area at compensation rates between $\$ 3 / \mathrm{kW}-\mathrm{yr}$ and $\$ 100 / \mathrm{kW}-\mathrm{yr}$.

Under existing BPA DSI contracts, approximately 650 NW of Puget Sound area peak load can be interrupted for a period of 15 minutes to provide capacity reserves. Under the contract half of the interrupted load must be restored after 15 minutes and the remainder must be restored after an additional 30 minutes. Any continuing curtailment after that point would be arranged 
informal1y between BPA and the affected DSI. Other Puget Sound area utilities can curtail smaller amounts of load but only during hours of the day that would be less useful in alleviating a potential voltage collapse. As these contracts expire and are renegotiated, it may be possible to increase curtailment rights. However, BPA's existing DSI contracts don't expire until the year 2001 and may not provide any additional near term curtailment potential. There is also no assurance that the DSI's will agree to additional curtailment provisions because of operational impacts.

Curtailment Cooperatives. The study team estimated that between $50 \mathrm{MW}$ and 300 MW of curtailment could be achieved over a 3 -year phase-in period through curtailment co-ops in the puget Sound area. Co-ops are groups of commercial and industrial customers who join together to provide contracted amounts of curtailment when called for under an interruptible rate. The co-op members agree to limit their collective demand, upon utility request, to preestablished firm service levels. The estimate is based on results in other parts of the country for similar sized load bases. The actual amount achieved wild depend on how the co-ow was structured and how aggressively area utilities sought this type of curtailment.

Co-ops in other areas of the country have required significant utility staff effort to seek out co-op participants and to establish reasonable firm service levels. In many cases the utility provides a number of customer service engineers whose function is to analyze each interested participant and establish potential load reduction strategies and amounts. In order to establish a curtailment base in the Puget Sound area, staff would need to be allocated to identify the potential. Whether the staff would be provided by individual utilities or a regional entity is an open question.

Other utilities have based compensation on the avoided cost of the least cost alternative replacement resource. A preliminary look at compensation based on BPA's costs and alternative pricing structures indicates that comrensation to co-ops would range between $\$ 3$ and $\$ 25 / \mathrm{kW}-\mathrm{yr}$. The avoided costs for Puget Sound area utilities would vary, but are assumed to be similar to BPA's.

Study team members expressed concern that, although some amount of curtailment could $f$ it into an overall strategy, load curtailment is not preferred as the primary long term solution. Historically, the Pacific Northwest has been accustomed to an abundant supply of electricity available on demand. Recent changes in the price and availability of electric power may make it economic to look toward increasing contractual rights to interrupt service as a supplement to other resources in achieving load-resource balance. When asked to compare the limitation of electricity supply (curtailment) to other approaches, most study participants preferred to use load curtailment as a last resort. It was viewed primarily as an emergency resource or short term measure to be used only until the implementation of a long term solution. However, curtailment could be incorporated into long-term planning as a tactic for use in response to low-probability contingencies, such as extreme weather, where the cost of system additions would be uneconomic based on infrequent use.

Most customers, including the larger industries in the Puget Sound area, would be willing to curtail some load to help local utilities keep the electrical 
system on line in an emergency, but would be less willing to participate if load curtailment was used as the primary solution to a longer term problem. Thus, the study team concluded that load curtailment would best be used as a short term measure or as part of a more comprehensive solution strategy.

Factors which were found to affect the industries' willingness to participate in any load curtailment program included the amount of warning, the frequency of curtailments, the duration of each curtailment, and the price utilities would be willing to pay. More warning would allow processes to be shut down safely and economically and decisions to be made regarding process schedules. Most industries agreed that as curtailment was used more of ten and for longer periods of time, fewer customers would be willing to participate. The survey also confirmed that the more utilities offered to pay for curtailment, the more willing customers would be to participate. However, some customers indicated unwillingness to participate regardless of the level of compensation. A few indicated that the amount of curtailment they could provide would not increase with greater compensation. Most responded that the effects of less warning, greater frequency, and longer duration of curtailments would tend to cancel out the incentive of highei compensation. Some industries stated that if they were asked to curiail load too of ten, they would not be willing to participate no matter what price incentive was offered.

Implementation issues that would need to be addressed include:

1. Priority, duration, frequency, \& amount of notice needed.

2. The means by which load curtailment would be implemented. (undervoltage, transfer trip, SCADA based)

3. Load curtailment as a reduction of reliability and if/how existing rate structure for some classes of customers would need to be changed. Some utilities don't feel existing rates would allow for curtailment on a planned basis.

4. The health and safety problems various types of load curtailment resources would create, including public safety problems.

5. How companies served by multiple utilities would be affected by each utility asking for curtailment. Would they be able to choose what they would curtail even though it meant possible curtailment to only one utility?

6. How do the u'.ilities keep from "crying wolf", especially with voluntary curtailment, so that the needed amount of curtailment is realized?

7. Public awareness, education, and communications problems. Does the public know how to react when curtailment is in effect? (turning of $f$ electrical appliances, lights, etc.)

8. How existing curtailment rights with DSI's apply to a load curtailment alternative. Some DSI's don't think the existing contracts were mean. to solve the problem being studied. 
Table IV-D-2

\section{LOAD CURTAILMENI SUPPLY CURVE}

\begin{tabular}{lcc} 
Program & Sector & Cost to \\
Utility & $(\mathrm{MW})$ & $(\$ / \mathrm{kW}-\mathrm{yr})$ \\
\hline
\end{tabular}

Year: 1992

Voluntary Curtailment

Al1

$10-860$

0

Curtailment Co-ops

Commercial/Industrial

0

0

Contractual

Industrial

0

0

Rolling Blackouts

A1 1

(1)

0

Year: 1993

Voluntary Curtailment

A11

$10-860$

0

Curtailment Co-ops

Commercia1/Industrial

$20-100$

$3-25$

Contractual

Industrial

$50-450$

$3-100$

Ro11ing Blackouts

Al1

(1)

0

Year: 1994

Voluntary Curtailment

Curtailment Co-ops

A11

$10-860$

0

Contractual

Conmercial/Indistrial

$40-200$

$3-25$

Industrial

$100-900$

$3-100$

Rolling Blackouts

A11

(1)

0

Year: 1995 and Beyond

Voluntary Curtailment

A11

$10-860$

0

Curtailment Co-ops

Commercial/Industrial

$50-300$

$3-25$

Contractual

Industrial

$100-900$

$3-100$

Rolling Blackouts

A11

(1)

0

(1) Resource could provide whatever MW requirements necessary but may be limited by recovery peak problems. 


\section{EVALUATION METHODOLOGY}

Introduction. This chapter describes the methodology for evaluating alternative strategies that address the Puget Sound area peak load problem. It will be used in the Environmental Impact Statement (EIS) being prepared for this project.

Following quantification of the supply and cost of the measures available to address the peak load problem, as discussed in the previous chapter, a key step in the evaluation process will be the construction of alternative strategies. (See Chapter VI) It is likely that these strategies will include components from more than one measure category. Evaluation and ranking will then be performed on these strategies for each of eight evaluation factors, as shown in the example evaluation matrix (Table V-1). Each evalution factor is described in detail later in this chapter.

The evaluation factors represent a range of concerns that utility decision makers may consider. Some factors, such as system costs, can of ten be quantified while others, such as environmental impacts, lend themselves more to qualitative comparisons. Evaluation factors dealing with utility costs treat the Puget Sound area as if it were served by a single utility. Issues of who will pay for what portion of an alternative strategy will not be dealt with in the EIS. Since the evaluation factors represent different concerns and are measured in different ways, the evaluation methodology ranks alternative strategies according to each factor individually rather using a single score that combines ranks from all factors. The methodology therefore does not weight the relative importance of each evaluation factor.

Among the alternative strategies considered, it is unlikely that the same strategy will rank highest on all evaluation factors. For example, the strategy with the lowest near-term revenue impacts may not be the strategy with the lowest present value of system costs. Eventually, tradeoffs must be made when searching for the best strategy.

Study Framework. The evaluation factors include measures of economic impacts and risk. Each of these factors focuses on the Puget Sound area as if it were served by a single utility. This single utility perspective means that no distinction is made between private and public utilities or load served by BPA and load served by utility-owned generation. The evaluation factors that consider revenue impacts include only the costs to utilities. In addition, the present value of total system costs and the measure of economic risk includes consumer costs and benefits as well as those of the utilities. For the latter factors, the perspective is that of society as a whole in the Puget Sound area.

The base case for this study assumes medium load growth in the Puget Sound area and will also account for currently planned generation, conservation, load management, and transmission additions. The study period for decisions will begin in winter 1993-94 and extend until winter ?002-03. End effects af ter 2003 will be accounted for. Table V-2 contains the proposed economic and financial assumptions for the evaluation of the alternative strategie. 
TABLE V-1

EXAMPLE EVALUATION MATRIX

\begin{tabular}{|l|c|c|c|c|c|}
\hline Evaluation Factor & Strategy A & Strategy B & Strategy C & Strategy D & Strategy E \\
\hline Minimize Net Present Value & 2 & 4 & 1 & 3 & \\
\hline Ability to Meet High Loads & 1.5 & 3 & 5 & 1.5 & 4 \\
\hline Minimize Economic Risk & 5 & 2.5 & 1 & 2.5 & 4 \\
\hline Minimize Near-Term Revenue Rgmts & 4 & 5 & 1 & 2.5 & 2.5 \\
\hline Minimize Long-Term Revenue Rgmts & 5 & + & 3 & 1.5 & 1.5 \\
\hline Minimize Environmental Impacts & 2 & 4 & 1 & 5 & 3 \\
\hline Maximize Deliverability & 3 & 3 & 1 & 3 & 5 \\
\hline Maxinize Reliability & 3 & 4 & 5 & 1.5 & 1.5 \\
\hline
\end{tabular}

\section{Notes}

These examples are for illustration purposes, and are not intended to represent particular stralegies Ranking: $1=$ high, 5 = low

Ties indicate rankings that are close together 


\section{ECONOMIC \& FINANCIAL ASSOMPTIONS}

Discount Rate

Inflation Rate

Cost of Capital

Percent Debt Financing
3 percent real

5 percent

4 percent real

100 percent 
After the base case is established and the eight evaluation factors are assessed, sensitivity studies will be performed where appropriate. Three likely candidates for variables to study are the discount rate, fuel prices, and the penetiation rates assumed for conservation and load management programs. This latter parameter is particularly important for assessing the uncertainty of the amount of conservation and load management available. Sensitivity analysis will be performed only on the economic evaluation factors.

Evaluation Factors. The following paragraphs describe each of the evaluation factors in detail. Of the eight evaluation factors, the first seven have been applied by utilities in the region for various resource planning exercises and have previously received public review. The eighth factor is new for this project and specifically addresses the issue of power system reliability. Methods of measurement have been designed to address the issues important to power system reliability in the Puget Sound area.

Minimize the Present Value of Total System Costs. For this evaluation factor, quantifiable costs and benefits of both energy and capacity, for resource and transmission actions, are used to calculate the net presenc value of total system costs for each alternative strategy. The present value includes costs and benefits to BPA, Puget Sound area utilities, and consumers. An expected value of three load paths: low, medium, and high will be used. Each proposed alternative strategy that solves the peak load problem in the Puget Sound is ranked according to this evaluation factor. The strategy with the lowest system cost then is ranked first for this factor.

System costs for this calculation include capital costs for actions that require construction, and debt service, operating and maintenance costs, regardless of whether these costs are paid by utilities or consumers.

Benefits include the energy and capacity saved or generated that benefit the power system. Marginal costs of energy and capacity will be used to value these benefits.

Ensure that Puget Sound Area Utilities are Able to Meet High Peak Loads from 1996-1998, if Necessary. Every utility faces uncertainty about what its future power needs will be. Even if load growth moderates in the Puget Sound area, utilities will need to initiate action in order to ensure that the criteria for system planning are met to serve peak loads safely and reliably. If, however, load growth continues over the next few years at the current pace, the risk of blackouts or other load interruptions becomes unacceptable if no actions are taken. For this factor, each alternative strategy will be evaluated in terms of its ability to meet forecasted high peak loads in the Puget Sound area on average from 1996 to 1998. This ability will be expressed in MW of capacity surplus or deficit. These years were chosen to allow enough time for utilities to implement reasonable actions to address the peak load problem once they realized they were experiencing continued high load growth. Using an average of 3 years ameliorates the "lumpiness" of large measures (such as transmission lines and combustion turbines) that arrive all at once in a particular year. 
Minimize Exposure to Economic Risks of Adjusting to Unplanned Changes in Load Growth, Resource Availability, and Costs. In addition to the risk of not serving peak loads, utilities and consumers run the risk of experiencing the economic impact of having chosen the wrong strategy to solve the Puget Sound area peak load problem. Two major areas of risk exist: (1) the cost of building or acquiring an expensive resource and/or transmission 1 ine that is not needed because load growth does not occur as anticipated (overbuilding); and (2) the high cost of acquiring expensive short lead-time resources because of greater load growth than planned (underbuilding). Economic risk for each alternative strategy will be measured by calculating the expected present value of total system costs assuming low and high load growth when the strategy has been designed for medium load growth.

Minimize Near-Term Revenue Requirements. Resource and transmission actions paid for by utilities require funding that must be recovered through revenues from rates charged to consumers. For this analysis, in keeping with the single utility perspective, funding sources will not be distinguished. Maintaining low and stable rates to customers is important to all utilities in terms of maintaining competitiveness and supporting the economic health of their customers. This factor will be measured by considering the average impact on utilty revenue requirements for the representative years 1996-1998 required to pay for each alternative strategy.

Minimize Long-Term Revenue Requirements. Long-term revenue requirements are also important for decision makers to consider. Strategies with the least. impact on near-term revenue requirements may have large adverse impacts on long-term revenue requirements. This factor will be measured in a manner similar to that used for the near-term revenue requirement impacts. It will consider the average impact on revenue requirements for the representative years 2006-2008.

Minimize Local and Global Environmental Impacts. For each alternative strategy, the costs of mitigation actions, such as installing scrubbers on coal plants, are included in total system costs. In contrast, this factor focuses on the nonquantifiable local and global environmental impacts of each alternative strategy, such as impacts on endangered species, wetlands, anadromous fish, air quality, and water quality. This factor will be a major focus of the EIS. It is discussed more thoroughly in the following chapter.

Maximize Deliverability in View of Social and Political Factors. In every decision process, factors other than economic or financial impacts affect the final decision. These influences are largely political and/or social and can strongly affect whether or not an alternative strategy is practical and achievable. For example, a technology or action may be well known and proven, but not publicly acceptable, and therefore would be difficult to implement. This factor attempts to assess the impact of elements such as regulatory influences, institutional complexity, and public acceptability on the ability to implenent each alternative strategy. There likely will be some overlap between this evaluation factor and the environmental impact factor, as well as others. However, in addition to the actual environmental impacts, this factor assesses how the perception of environmental impacts may affect the feasibility, or deliverability, of a particular alternative. 
It does not necessarily follow that the alternative with the fewest or most benign environmental impacts will be the most deliverable. Finally, in contrast to the other evaluation factors, this factor is largely the result of judgment.

Maximize Power System Reliability. Reliability is a measure of the capability of the power system to meet consumer demands over a period of time. It is typically measured in terms such as how of ten outages occur, how long they last, and how much load is affected. The goal is to maximize reliability to the extent possible.

Planners use a set of rules, such as the BPA Reliability Criteria, to establish reliability requirements for the power system. The criteria specify contingencies that must be examined, such as the loss of a key transmission line or generating station, and define acceptable performance, in this case serving extreme winter peak loads. At this point, no explicit measure of reliability is made. However, the criteria reflect a balance between the cost of upgrading the power system to provide a given level of service and the benefits to the consumer in terms of reduced outage impacts, based on the experience of system planners.

All proposed strategies must meet the tests specified in the criteria. However, even after meeting the tests, each strategy may provide a different level of reliability. For example, two transmission circuits on a single tower pose a greater risk than if they are routed on separate corridors, but they both satisfy the reliability criteria.

Existing transmission reliability models are not capable of examining the Puget Sound peak load problem because of the complexity of the system and the difficulty of detecting voltage collapse. Therefore, a simplified analysis will be performed for this evaluation factor. Power flow studies performed by the transmission study team will determine the amount of load that can be served with a major facility, such as a 500-kV cross-mountain line, out of service.

Load and system capability information will be combined to determine the likelihood and severity of system problems, similar to a generation capacity study. Daily and seasonal load variation will be considered, as well as higher loads resulting from cold weather. The measure of reliability for this evaluation factor is expected MW-hours unserved. 


\section{NEXT STEPS: PHASE II}

Introduction. This chapter describes the next phase of the technical and environmental components of the analysis. It also discusses the interim steps being taken to address operating concerns while a longer term solution is sought. Upcoming public involvement opportunities are discussed in Part $A$ of this report.

Development of Alternative Strategies. The first task in Phase II of the study will be to develop alternative strategies from among the measure categories. This aggregation will allow planners to balance costs and risks, and to take advantage of the relatively short lead times required to develop some alternatives. Some strategies may consist of only one measure category, but most will probably include elements of two or more categories.

Chapter IV presented cost and quantity data for options within each measure category. Where appropriate, taking into account cost and lead times, these elements will be aggregated into logical groups to simplify the analysis. For generation, groups of resources such as small hydro or cogeneration may be aggregated. Conservation, load management, and curtailment measures may be grouped into blocks of related programs or technologies where appropriate. One transmission measure representing line construction and a second measure using only reactive sources will be considered. To be considered for further analysis, an aggregate strategy must pass the tests specified in the reliability criteria.

Examination of the strengths and weaknesses of each measure should provide guidance in assembling the alternative strategies. For example, a transmission line may completely fix the problem for 10 years, but it requires about 6 years to site and build. As a result, any alternative strategy that includes transmission line construction needs to include measures that address the peak load problem in the years prior to the completion of the line, such as load curtailment, On the other hand, load management may be cost effer:tive for deferring a transmission line for some period of time, thus delaying or avoiding the need for the line. These examples illustrate the types of tradeoffs to be considered as these alternative strategies are formed. In this way, four to six alternative strategies, representing the range of possible actions, will be developed for analysis in the planning EIS.

Environmental Analysis - Planning Phase EIS. Environmental analysis is planned on four levels. The first level is the application of environmental screening factors. These factors recognize unique habitats and protected sites as well as environmental quality standards that any proposal must meet to be approved. 
The environmental screening factors differ from the screening factors discussed in Chapter IV in that they constitute absolutes, and no alternative would be considered viable if it violated a legal requirement. Table VI-1 is a list of the environmental screening factors.

The second level is a generic assessment of environmental impacts, to be based largely upon published findings for similar projects. Impacts associated with each alternative will be 1 isted in matrix form to allow comparison.

The third level is a locational impact assessment. In the absence of a proposed site (as in this planning phase EIS) little can be said about how an action will affect actual environments. This analysis provides a geographical context to the impact analysis. The locational assessment is based on a geographical data base composed of natural resource and cultural resource data. Data within the data base have been used to build impact sensitivity models for each of the measure types being considered for the Puget Sound area. The result of the locational assessment will be a series of impact advisory maps that predict environmental sensitivity as high, moderate, or low. This technique is most commonly attributed to Ian McHarg, and has been described as an ecologically based approach to urban and regional planning.

Finally, once the impacts of each measure are analyzed and understood, a yet-to-be-developed method of providing environmental advice on alternative strategies will be developed. It is expected that the final method will extrapolate findings at the component level and reflect relative environmental differences among strategies. It may be useful to use strictly environmental factors to assemble what might be the strategy with the least environmental impact, and compare all other strategies to it. The specifics of this fourth level of analysis will be developed during Phase II.

Near Term Actions. BPA and the Puget Sound utilities have worked through the Northwest Power Pool to develop a "Winter Operating Plan" to deal with possible near term system emergencies. Under the plan, measures are to be implemented by each of the parties when loads reach specified levels or when a system disturbance occurs. Measures include "arming" the system to curtail direct service industrial load automatically; operating thermal generation to support system stability before it would be economically justified; and, as a last resort, instituting utility curtailment by geographical area ("rolling blackouts"). The plan was put into effect during winter 1989-90 and is being refined for 1990-91.

The group is also investigating low cost, environmentally benign actions that can be taken now but will fit into the long term strategy. Such actions might include adding capacitor banks and static VAR devices and installing under-voltage load shedding equipment. 
ENIROMENTAL SCREENING FACTORS

\section{AVOIDS PROTECTED SITES AND ENVIRONMENTALLY UNIQUE HABITATS}

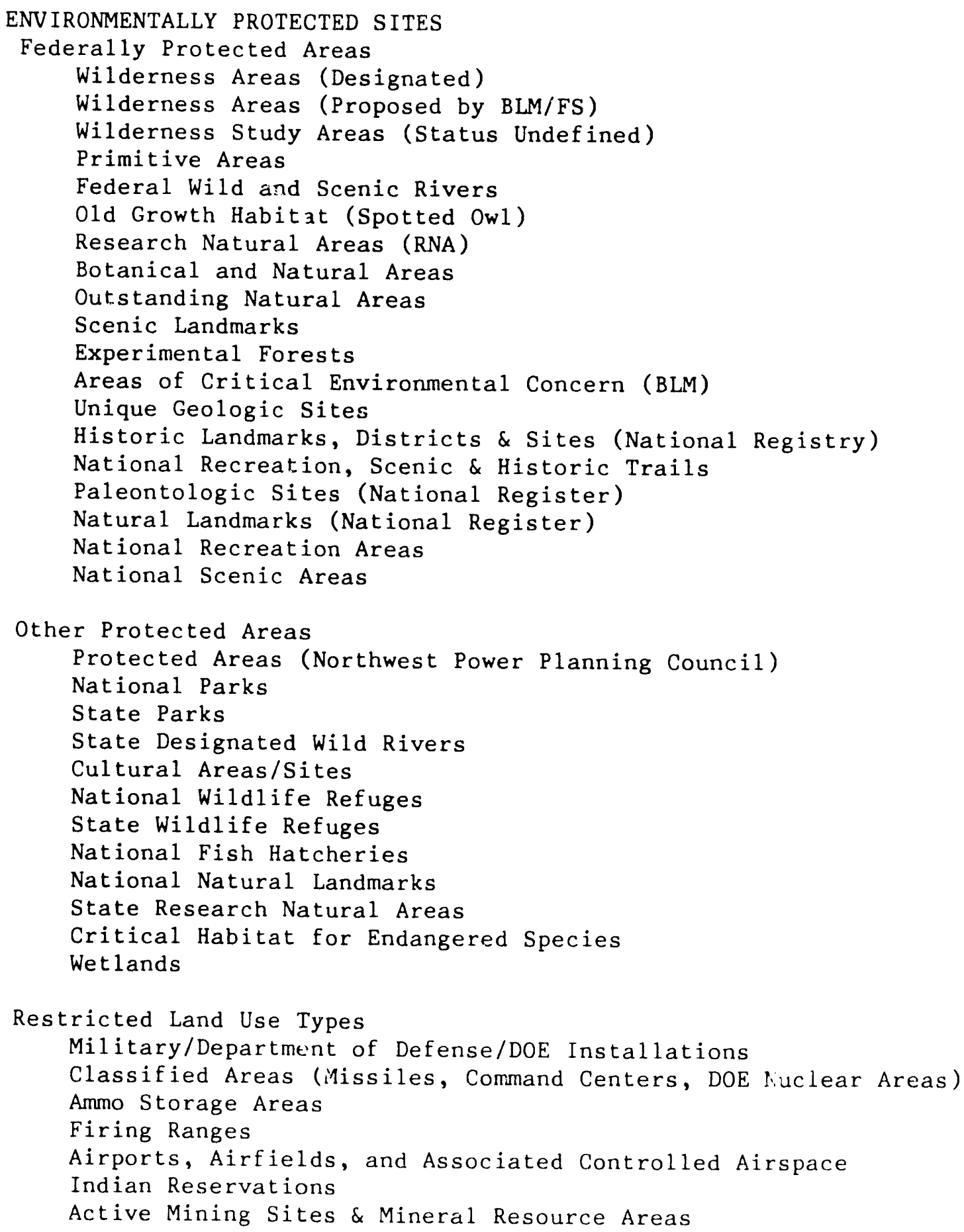


2. MEETS ENVIRONMENTAL QUALITY STANDARDS

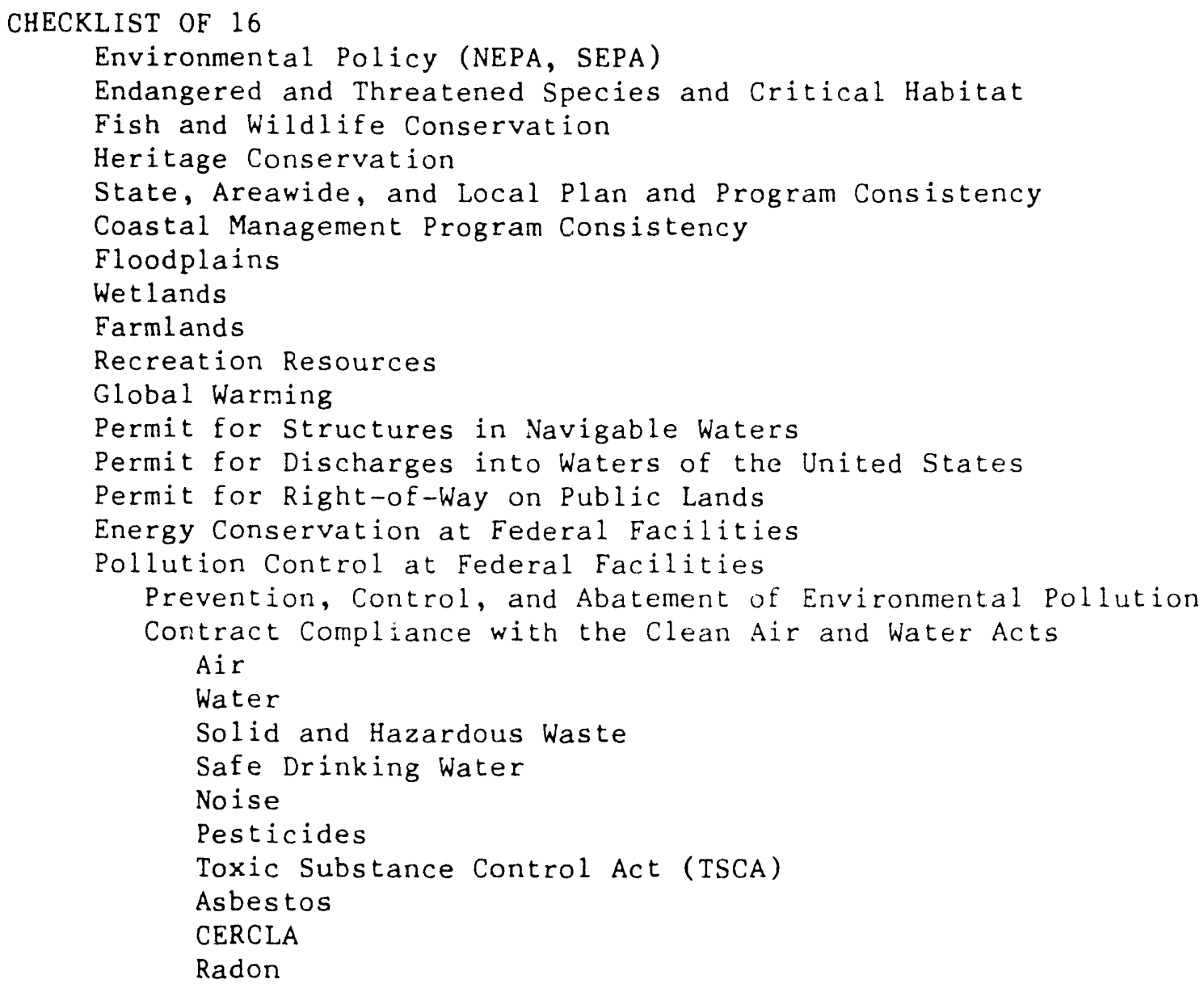

(VS11-T-1449f) 


\section{LETTER AGRESWISNT \\ Management of Paget Sound Reinforcement Project}

Under certain conditions, the East-Mest Main Grid Transaission Systen is no longer able to support the increasing electrical loads in the Puget Sound Area due to rapidly increasing load growth. In response to this growing problen, the Bonneville Power Administration (BPA) has initiated a Federal NEPA process to evaluate potential solutions.

BPA and various Puget Sound area utilities, including Public Utility District Number 1 of Snohouish County, Puget Sound Power \& Light Company, Seattle City Light, and Tacoma City Light (collectively, the "Puget Sound Utilities") have agreed to cooperate at several organizational levels in further defining the problen of voltage instability in the Puget Sound area, and evaluating potential solutions. Currently, under conditions of peak winter demand, the systen aight not adequately withstand failure of a major line or the Centralia power plant.

BPA and the Puget Sound Utilities agree that the Puget Sound Reinforcement Project, which BPA has initiated to address the voltage instability issue, should be an effort that adequately addresses the NEPA and SEPA needs of all parties to the extent applicable. The potential results of voltage instability in Paget Sound are not yet fully known, but BPA and the Puget Sound utilities seek to jointly explore the existence and extent of the problem as well as cost-effective environmentally sound solutions to this problem to the extent possible. This letter reflects the comitment by the undersigned to coordinate on this planning effort. It is the intent that the decisions of the 5 utilities will be by consensus.

1. Steering Committee. A Steering Committee, composed of a single representative from Bonneville and each of the Puget Sound Utilities, is established. The purpose of the Steering Comittee, through a Project Management Team and various study teams, is to:

- provide organizational support for the completion of studies addressing the voltage instability problem;

coordinate the NEPA/SEPA process, including the preparation of any environmental disuments;

analyze the evaiuation criteria for alternatives;

- analyze the alternatives;

- coordinate with other Federal, State, and local agencies; and

- conrdinate public involvement efforts. 
BPA, consistent with its lead role in the Federal EIS, will chair the Steering Comittee. Hembers are the signatories to this letter.

2. Project Hanagement Tean. BPA and each of the Puget Sound Utilities will desigmate a Project Manager. The purpose of the Project Management Team will be to conduct the studies and carry out the tasks established by the Steering Comittee. The BPA representative will chair the Project Hanagement Team. The Project Kanagenent Tean will conduct work through various study teans which will address subjects including, but not limited to, load forecasting, local generation, load curtailment, conservation/demand side management, transmission studies and evaluation criteria.

3. Technical Review Group. A Technical Review Group is established as an advisory group to the Project Hanagenent Team. Hembership in the rechnical Review Group will be open to interested utilitiec, interest group leaders, State and Federal agency representatives, and others interested in providing specific technical input on studies, options and alternatives, and decision criteria. The BPA Project Hanager will provide leadership for this group, including the setting of meetings and agendas and arranging for input to the Project Management Tean.

4. Funding. BPA and the participating atilities will separately fund their participation in the planning process described in this letter. Nothing in this letter precludes BPA or the Puget Sound Utilities from seeking rate relief for costs associated with this project through their respective rate processes.

5. Impact. BPA and the Puget Sound Utilities agree that the process described in this letter is intended solely as a coordinating vehicle and is not itself intended to replace, impact, or prejudice any existing or future individual utility efforts.

6. Termination. BPA and the Puget Sound Utilities agree that any member of this planning process may terminate its participation upon notice to the other participants. 
(Letter Agreement - contd.)

3

PUBLIC UTILITY DISTRICT \#1 OF SNOHOMISH COUNTY

or Cheslux in Sect

Date $3 / 22 / 90$

BONNEVILLE POWER ADMINISTRATION

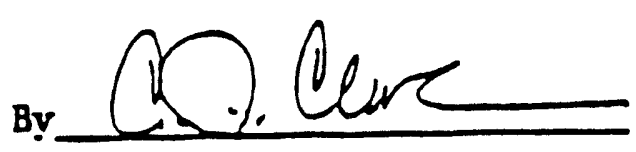

PUGET SOUND POKER \& LIGHT COMPANY

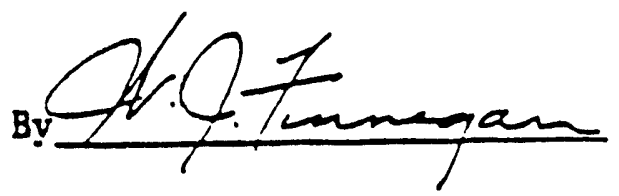

SEATTLE CITY LIGHT

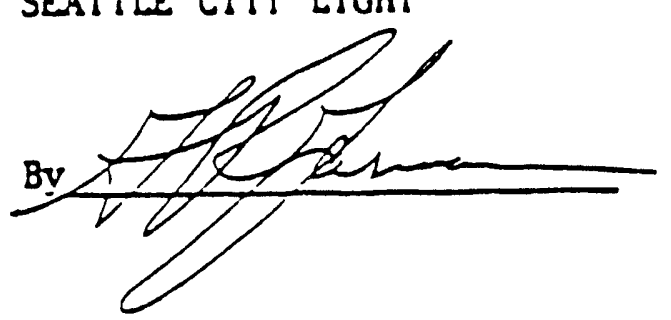

TACOMA CITY LIGHT

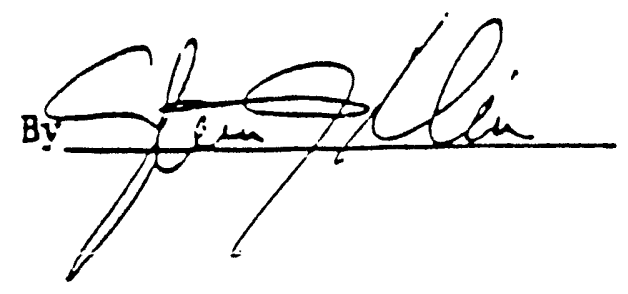

Date $3 / 9 / 90$

Date $3 / 13 / 20$

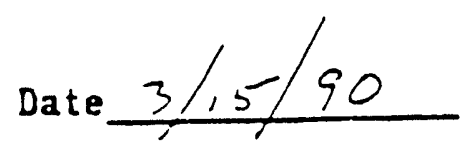

Date 3/19/40 

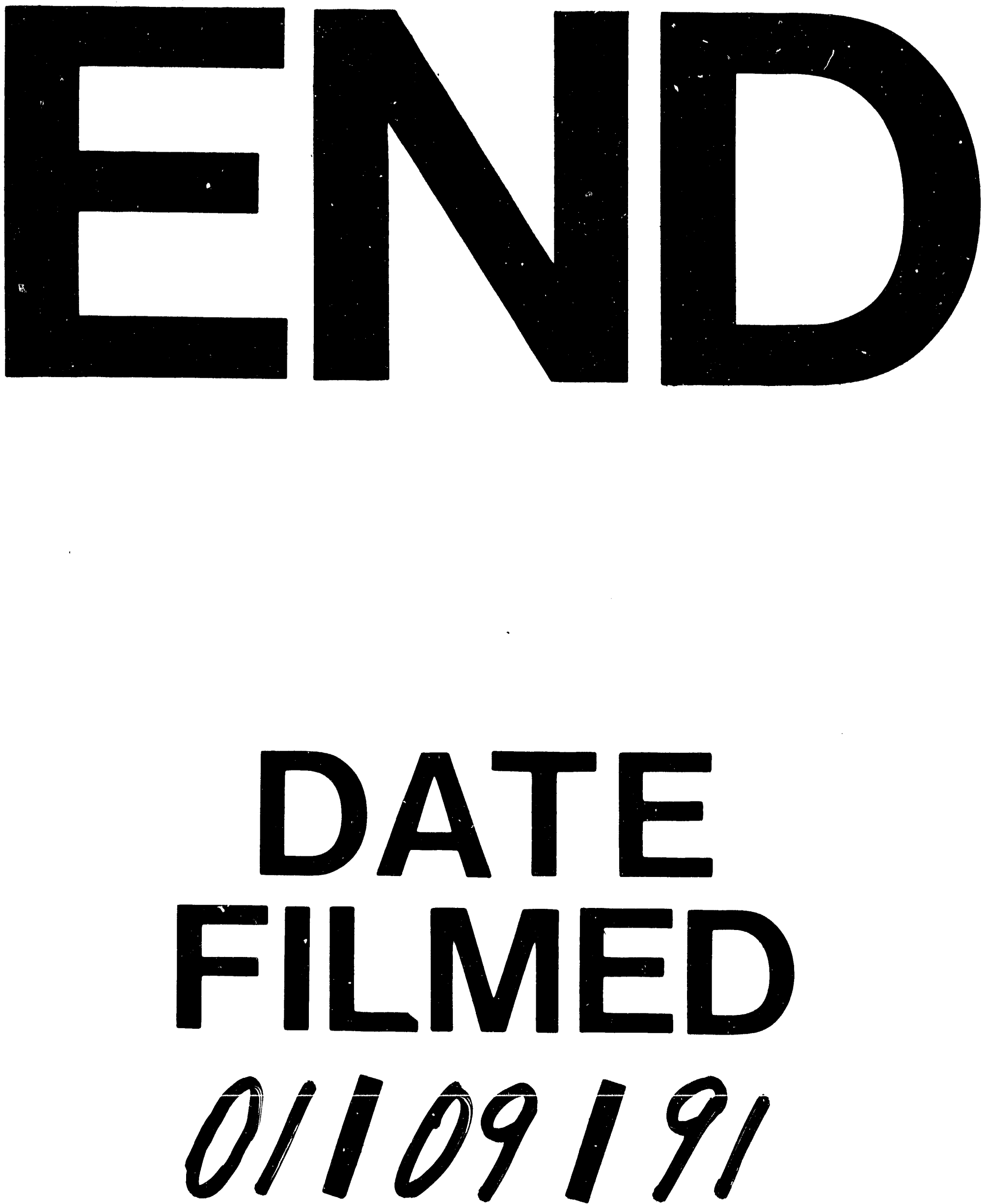

1

$-\cdots$ 